\title{
Prediction of response to escitalopram across multiple outcomes in older adult GAD patients
}

Caroline M. Ciliberti

West Virginia University

Follow this and additional works at: https://researchrepository.wvu.edu/etd

\section{Recommended Citation}

Ciliberti, Caroline M., "Prediction of response to escitalopram across multiple outcomes in older adult GAD patients" (2010). Graduate Theses, Dissertations, and Problem Reports. 2995.

https://researchrepository.wvu.edu/etd/2995

This Thesis is protected by copyright and/or related rights. It has been brought to you by the The Research Repository @ WVU with permission from the rights-holder(s). You are free to use this Thesis in any way that is permitted by the copyright and related rights legislation that applies to your use. For other uses you must obtain permission from the rights-holder(s) directly, unless additional rights are indicated by a Creative Commons license in the record and/ or on the work itself. This Thesis has been accepted for inclusion in WVU Graduate Theses, Dissertations, and Problem Reports collection by an authorized administrator of The Research Repository @ WVU. For more information, please contact researchrepository@mail.wvu.edu. 


\title{
Prediction of Response to Escitalopram Across Multiple Outcomes in Older Adult GAD Patients
}

\author{
Caroline M. Ciliberti
}

\author{
Thesis submitted to the \\ Eberly College of Arts and Sciences \\ at West Virginia University \\ in partial fulfillment of the requirements \\ for the degree of
}

\section{Master of Science}

In Psychology

\section{Barry Edelstein, Ph.D., Chair \\ Kevin Larkin, Ph.D. \\ Julie Patrick, Ph.D. \\ Department of Psychology}

Morgantown, WV

2010
Keywords: Generalized Anxiety Disorder, Older Adults, Worry, Treatment Copyright 2010 Caroline M. Ciliberti




\begin{abstract}
Prediction of Response to Escitalopram Across Multiple Outcomes in Older Adult GAD Patients
\end{abstract}

Caroline M. Ciliberti

Anxiety disorders are common in late-life and have detrimental effects of health and well-being (Stanley, Diefenbach, \& Hopko, 2003; Wetherell et al., 2004). Generalized Anxiety Disorder (GAD) is the most common anxiety disorder in late-life (Beekman et al., 1998). Beyond the diagnostic symptoms, older adults with anxiety disorders may present with a variety of physical symptoms (Palmer, Jeste, \& Sheikh, 1997). As a result, GAD is a heterogeneous disorder. Empirically-supported treatments are available for latelife GAD, but little is known about how people with different constellations of presenting symptoms respond to treatment, and whether they differ according to the way in which improvement is measured. The present study aimed to identify which presenting symptoms differentiated older adults with GAD from those without and how those symptoms predicted outcome across several domains of response. Participants were enrolled in a trial testing the efficacy of escitalopram for treatment of late-life GAD. One hundred and seventy-seven older adults with GAD and 41 older adults with no diagnosis participated. One hundred percent of the cases were correctly classified on the basis of the "Anxious Mood" and "Tension" SIGH-A items. A subset of participants with GAD who had been randomly assigned to received escitalopram and had completed 12 weeks of blinded treatment were further analyzed. Neither "Anxious Mood" nor "Tension" significantly predicted outcome in any domain. However, baseline scores on several of the outcome measures accounted for a significant amount of variance in week 12 scores, with lower scores being associated with better outcomes. These results indicate that baseline scores are the best predictors of outcome, and could have implications for treatment of GAD in late-life. 


\section{Acknowledgements}

Many thanks to my committee chair and advisor, Barry Edelstein, for his insightful comments and guidance with this project. I am also incredibly grateful to my other thesis committee members, Kevin Larkin and Julie Hicks Patrick. Their advice and feedback truly helped to shape my work.

Finally, I would also like to thank my family and Jim. Your patience, support humor, and love helped to motivate me through this process. 


\section{TABLE OF CONTENTS}

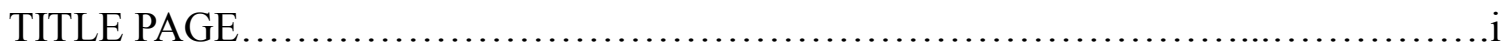

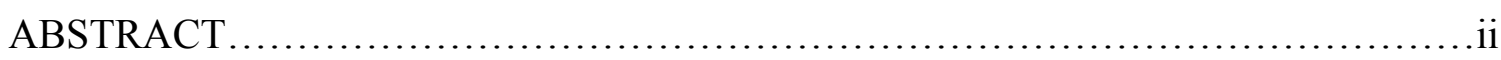

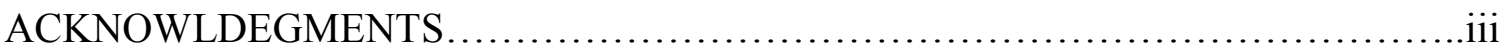

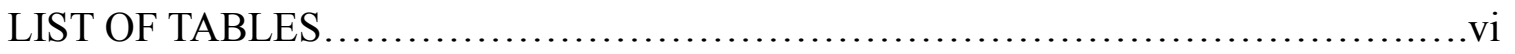

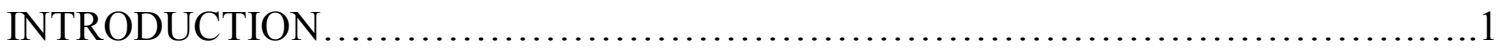

Generalized Anxiety Disorder............................................

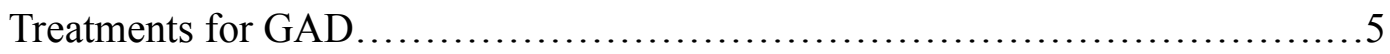

Predicting Treatment Response.........................................

Evaluating Treatment Outcomes...................................... 9

STATEMENT OF THE PROBLEM........................................... 10

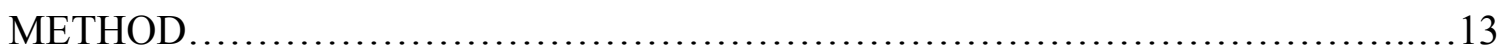

Participants....................................................... 14

Materials............................................................... 15

Structured Interview Guider for the Hamilton Anxiety Rating Scale......15

Penn State Worry Questionnaire................................16

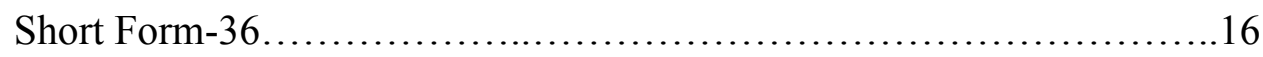

Clinical Global Improvement Scale- Improvement....................17

Salivary Cortisol.............................................. 17

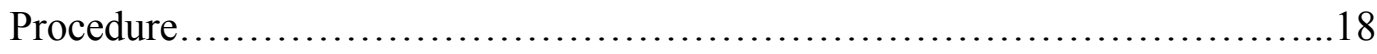

RESULTS.............................................................19

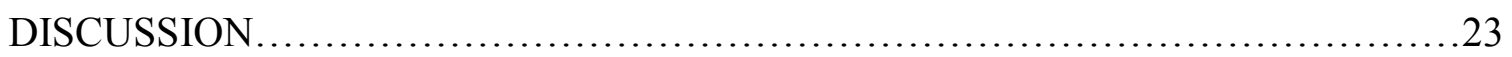

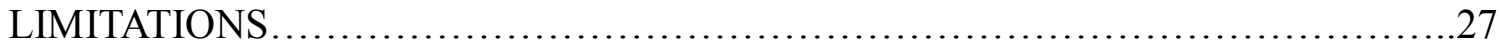


FUTURE DIRECTIONS AND CONCLUSIONS ...............................28

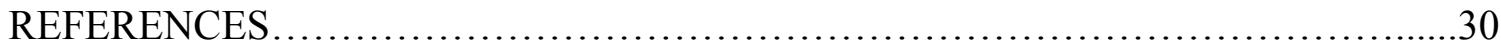

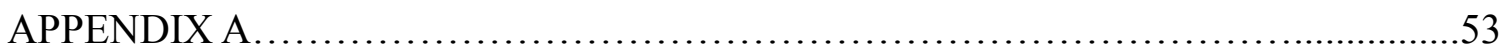

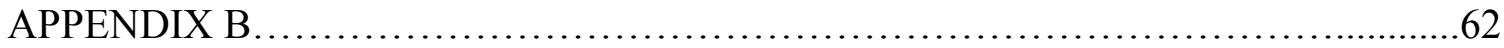

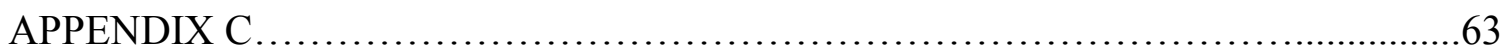

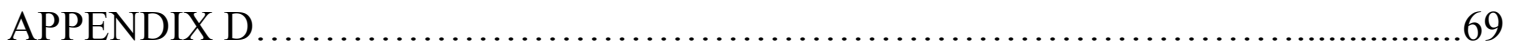




\section{LIST OF TABLES}

Table 1. Predictor Variables and Treatment Outcome Measures for Pharmacological

Interventions

Table 2. Predictor Variables and Treatment Outcome Measures for Psychosocial

Interventions

Table 3. Demographic and Participant Characteristics by Diagnosis

Table 4. Means for Outcome Measures for All Participants with GAD at Baseline

Table 5. Group differences for outcome measures at baseline and week 12 for participants with GAD who were randomized to medication .46

Table 6. Correlations Between Baseline and Week 12 Administration of Predictor and Outcome Measures.

Table 7. Differences Between SIGH-A Cluster Item Scores in the GAD and Control Group. .49

Table 8. Classification Results for Discriminant Function Analysis. .51

Table 9. Regression Models for Predicting Outcomes of GAD Using SIGH-A Clusters as Predictors 
Prediction of Response to Escitalopram Across Multiple Outcomesin Older Adult GAD Patients Anxiety Disorders are common in late life, affecting 10.2\% of older adults (Beekman et al., 1998). Despite their prevalence, anxiety disorders are often under-identified and underdiagnosed among older adults (Harman, Rollman, Hanusa, Lenze, \& Shear, 2002). There are several challenges to detecting and diagnosing anxiety disorders among older adults that may account for this. Most screening instruments were developed for use with younger adults and may be inappropriate for use with older adults. Older adults may differ from younger adults in how they report their symptoms. Specifically, older adults are more likely to underreport symptoms of psychological distress (Tweed, Blazer, \& Ciarlo, 1992), and may report different symptoms than younger adults, and are less likely than younger adults to report worthlessness associated with anxiety (Shapiro, Roberts, \& Beck, 1999). Further, older adults tend to be more exact when describing negative affective states (Shapiro et al., 1999), emphasizing the importance of capturing the lexicon of older adults when screening for anxiety disorders.

There are conflicting findings about somatic presentations of anxiety in older adults. For example, Christensen and colleagues (1999) found that older adults reported fewer somatic symptoms of anxiety on assessment instruments, such as headaches and physical tension, in comparison to younger adults. In contrast, some studies have found that older adults report more somatic symptoms than younger adults (Spar \& LaRue, 1990), and still others have found no difference in the reporting of somatic symptoms between age groups (Stanley et al., 2003).

Further complicating diagnosis, anxiety disorders frequently are comorbid with another Axis I disorder, or a physical disorder among older adults. Perhaps due in part to an overlap in diagnostic symptoms, $27.5 \%$ of older adults diagnosed with major depression are also diagnosed with an anxiety disorder (Lenze et al., 2000). People with anxiety disorders also have more 
physical comorbities, and greater physical disability than those without (Brenes et al., 2005; de Buers et al., 1999; Palmer, Jeste, \& Sheikh, 1997). Palmer and colleagues (1997) outline several possible factors that may explain this co-occurrence. First, both physical illness and anxiety are common in older adults, and thus co-occur. Second, some symptoms of anxiety are somatic. For example, palpitations and sweating may be manifestations of anxiety but are sometimes interpreted as signs of physical illness. It is also the case that anxiety might result from the stress of having a physical illness. Finally, some physical illnesses (e.g., hyperthyroidism) may present as anxiety, and some medications used to treat physical illnesses may cause anxiety as a side effect (Palmer et al., 1997). These factors make detecting anxiety in older adults challenging. As a result of these age-related differences in the experience and presentation of anxiety symptoms, the current diagnostic criteria may not adequately capture the experience and presentation of anxiety in older adults, leading to under-recognition. Thus, older adults may go undiagnosed with anxiety symptoms, resulting in a lifestyle associated with diminished well being, increased use of health services, more severe depression, and poorer social functioning (de Buers et al., 1999; Lenze et al., 2001).

Of the anxiety disorders, Generalized Anxiety Disorder (GAD) is the most common among older adults, affecting 7.3\% of community dwelling older adults (Beekman et al., 1998). GAD is associated with poorer quality of life (Bourland et al., 2000; Porensky et al., 2009; Stanley, Diefenbach, \& Hopko, 2003; Wetherell et al., 2004), and worse perceptions of mental and physical health (Stanley et al., 2003) than of individuals without this disorder. According to the Diagnostic and Statistical Manual of Mental Disorder, Fourth Edition (DSM-IV; APA, 1994) criteria, GAD is characterized by excessive and difficult to control worry about multiple events, occurring on most days for a minimum of 6 months. The worry is accompanied by three or more 
of the following six symptoms: restlessness or feeling edgy, being easily fatigued, trouble concentrating or mind going blank, irritability, muscle tension, and sleep disturbance. However, the proposed criteria for the $5^{\text {th }}$ edition of the DSM focus more on distress and impairment due to worry, requiring excessive and interfering worry and either restlessness or muscle tension to receive a diagnosis of GAD (APA, 2010). These proposed changes put more emphasis on the core symptom of GAD: worry. Many people with GAD expend a disproportionate amount of time worrying about everyday situations, and find it difficult to stop worrying. In addition to the diagnostic symptoms, some people with GAD experience an increase in somatic symptoms, such as upset stomach and sweating (APA, 1994). Though some worries (e.g., worries about family, and health of a loved one) seem to be common among all older adults, certain topics of worry have been shown to differentiate older adults with GAD from those without GAD (Wetherell, Le Roux, \& Gatz, 2003). These topics include worry about small matters, finances, personal health, and social matters (Wetherell et al., 2003). However, only 13.3\% of patients with GAD present for treatment with anxiety as their primary complaint (Wittchen et al., 2002). Instead, many present with physical symptoms (Flint, 2005; Wittchen et al., 2002). Because of the complicated nature of the link between somatic symptoms and anxiety in older adults, it is often difficult for providers to determine whether these presenting somatic symptoms are actual symptoms of GAD or a result of some physical illness. Wetherell and colleagues (2003) examined the associated diagnostic symptoms among older adults with GAD and older adults with no DSM diagnosis. Older adults with GAD were more likely than members of the control group to endorse trouble sleeping, muscle tension, fatigue, restlessness, and irritability. Sleep disturbance and muscle tension are especially salient among older adults with GAD. However, trouble concentrating did not distinguish those with GAD from the control group (Wetherell et al., 2003). Beck, Stanley, 
and Zebb (1999) also compared older adults with GAD to older adults with no DSM diagnosis. They found older adults with GAD differed in regard to categories of self-reported symptoms (i.e., tension and anxiety, somatic symptoms, and agitated behavior).

In addition to the diagnostic and presenting symptoms of GAD discussed above, neurobiological markers have been proposed for the identification of GAD. Some hypothesize that depression and anxiety are characterized by hypothalamic pituitary adrenal (HPA) axis dysregulation in the brain, resulting in abnormal levels of the stress hormone, cortisol (Mantella et al., 2008). Researchers can make inferences about HPA-axis functioning by measuring the production of cortisol. Researchers often measure salivary cortisol levels because it is a minimally invasive technique, and levels of salivary cortisol correspond with levels of serum cortisol (Hansen, Garde, \& Persson, 2008). It is important to examine the neurobiology of older adults because it is possible that there are significant changes with age. Studies of HPA axis activity in older adults have shown increases in activity associated with increased age (Van Caurter et al., 1996), and increases in mean levels of cortisol (Ferrari, Magri, Dori, Migliorati, Nescis, Molla, Fioravanti, \& Solerte, 1995). There is also evidence that HPA axis dysregulation may be linked to anxiety disorders in older adults. More severe GAD, as measured by the Penn State Worry Questionnaire (PSWQ) and the GAD Severity Scale (GADSS; Shear, Belnap, Mazumdar, Houck, \& Rollman, 2006), has been shown to be associated with higher levels of salivary cortisol (Mantella et al., 2008). Further, older adults with anxiety disorders show higher levels of cortisol after being exposed to stressors than older adults without anxiety disorders (Chaudieu et al., 2008). Chronic exposure to stress hormones may result in a host of negative outcomes, including impaired immune functioning and more cardiovascular stress. Such exposure also may contribute to the development of dementia (Mantella et al., 2008). 
When appropriately identified, there are several pharmacological and psychosocial evidencebased treatments available to older adults with GAD. Historically, benzodiazepines were used to treat anxiety in older adults, but because of significant risks, most prescribers have moved towards the use of antidepressants as a first line treatment of GAD (Sheikh \& Cassidy, 2000). The antidepressants venlafaxine ER and citalopram have been shown to be effective for treating GAD in older adults, resulting in improved clinical global impressions and improved Structured Interview Guide for the Hamilton Anxiety Scale (SIGH-A ; Shear et al., 2001) scores (Katz et al., 2002; Lenze et al., 2005). Escitalopram also has been shown to be effective for treating GAD, resulting in improvement in clinical global impressions, lower levels of worry (as measured by the PSWQ) and improved quality of life (as measured by the Short Form -36) (SF-36; Ware \& Sherbourne, 1992). Escitalopram is a selective serotonin reuptake inhibitor (SSRI) that has been shown to be an effective treatment for GAD (Goodman, Bose, \& Wang, 2005; Lenze, et al., 2009). In a pooled analysis of randomized controlled trials examining the efficacy of escitalopram in participants ranging from 18 to 80 , escitalopram was shown to be well tolerated and effective at reducing post treatment Hamilton Anxiety Rating Scale scores (Goodman, Bose, \& Wang, 2005). Several psychosocial treatments also have been shown to be efficacious among older adults with GAD. Relaxation training and cognitive-behavior therapy (CBT) have the most support for their efficacy in the treatment of GAD among older adults (Ayers, Sorrell, Thorp, \& Wetherell, 2007). A review by Ayers and colleagues (2007) found 9 studies supporting the use of CBT for treatment of GAD in older adults. For example, Mohlman et al. (2003) found that older adults with GAD receiving CBT showed a greater reduction in GAD severity at 6 months follow up than those in a wait-list control group. Stanley, Beck, and Glassco (1996) found that CBT treatment resulted in reduced anxiety, worry, and depression, as measured by GAD severity, the 
PSWQ, the Hamilton Anxiety Scale, the Worry Scale (WS; Wisocki, Handen, \& Morse, 1986), and the State Trait Anxiety Inventory - Trait (STAI-T; Spielberger, Gorsuch, \& Lushene, 1970).

Several of the studies discussed above used different strategies for measuring treatment response (e.g., a drop in scores on a measure of anxiety, a global rating of improvement, or a change in quality of life measures) and consequently used different definitions of response to determine whether an intervention was effective. These outcome measures are certainly helpful, but they may not adequately depict response to treatment.

Most of the research studies supporting both pharmacological and psychosocial treatments of GAD have measured improvement by examining changes in total scores on assessment instruments. Few studies have performed a fine grained analysis of the qualitative changes in individual anxiety symptoms with treatment. Lecrubier, Dolberg, Anderson, and Weiller (2008) examined qualitative changes in symptomatology with escitalopram treatment, by examining patterns of treatment changes in people with GAD, Major Depressive Disorder (MDD), and patients with mixed anxiety and depression. Their work focused largely on describing treatment effects by retrospectively examining the specific groups of symptoms that changed with treatment. Stein, Anderson, and Goodman (2005) pooled 3 antidepressant treatment studies, and examined changes in the symptom clusters assessed on the SIGH-A among adults with GAD. They found significant treatment effects for 7 of the 14 symptom clusters (anxious mood, tension, fears, insomnia, intellectual, depressed mood, and interview behavior). Though both the Lecrubier and the Stein studies took a closer look at the specific qualitative changes of anxiety symptoms with treatment, neither study focused on older adults with GAD. 
In addition to examining changes with treatment, researchers have attempted to identify pre-treatment variables that predict outcome (See Tables 1 and 2 for summaries). The ability to predict outcome based on pre treatment presentation may help providers make informed treatment decisions when planning patient care. Predictors of treatment response have been explored for both psychosocial and pharmacological therapies for the treatment of a variety of anxiety disorders (e.g., panic disorder and GAD). Some diagnostic symptoms (e.g., sleep disturbance) have also been shown to predict positive response to treatment, while others (e.g., restlessness) predict poorer outcomes (Pollack, Meoni, Otto, \& Hackett, 2003). A history of substance abuse has been shown to predict positive outcomes (Pollack et al., 2003), while recent benzodiazepine use has been shown to predict negative outcomes (DeMartinis, Rynn, Rickels, \& Mandos, 2000). Further, early improvement has been shown to be associated with better longer term outcomes (Rynn et al., 2006). Older age has been shown to predict poorer treatment outcomes, as have certain baseline comorbidities, including the presence of a personality disorder (Seivewright, Tyrer, \& Johnson, 1998). Haby, Donnelly, Corry, and Vos (2006) found that treatment studies that included samples with greater severity had poorer outcomes than those that didn't. Other study-design variables, including waitlist control, were associated with poorer outcomes. Durham, Allan, and Hackett (1997) found that being married was associated with more favorable outcomes, whereas marital stress was associated with poorer outcomes. Further, comorbid diagnoses were also associated with poorer outcomes.

Only one study has examined the factors that predict GAD treatment response in a sample of older adults. Wetherell and colleagues (2005) pooled data from 3 psychotherapy treatment studies for older adults. Outcome was measured using a Reliable Change Index, or RCI, for three measures: the GAD severity rating, Hamilton Anxiety Rating Scale (HAM-A), and PSWQ. 
The RCI is an outcome measure used to quantify treatment gains. Better outcomes were associated with higher GAD severity at baseline, presence of Axis I comorbidity, and more frequent homework (Wetherell et al., 2005).

In sum, several studies have examined demographic, psychiatric, and treatment variables that predict treatment response for GAD. However, only one (Wetherell et al., 2005) has used a sample of older adults, and only one (Pollack et al., 2003) has examined the predictive value of the different symptom presentations. There have been no studies that have examined the predictive value of common symptom presentations of anxiety, beyond those outlined by the DSM, and none that have examined the predictive value of symptom presentations in older adults. It is possible that the DSM does not adequately capture the experience of anxiety in older adults, considering the diagnostic challenges discussed above. Moreover, the DSM diagnostic symptoms are broad and vaguely worded (Brown \& Barlow, 2009). The threshold levels used to diagnose GAD are not based on empirical evidence, and are difficult to assess in clinical practice (Brown \& Barlow, 2009). Considering the unique presentations of anxiety in older adults, knowledge of how symptoms predict positive treatment outcome would be valuable.

Treatment outcome researchers have defined response in different ways. Some studies have relied on global measures of improvement, some on reduction in worry, and some on changes in physiological responses. However, it is unclear how these response measures relate to each other, and how the course of treatment may differ according to how one defines response. Typically, researchers rely on one outcome measure, assessing one response mode, to determine the efficacy of an intervention. Treatment studies of GAD frequently focus on either change scores on a single measure of anxiety (e.g., SIGH-A, HAMA, PSWQ), or measures of global improvement (e.g., CGI). However, some researchers (e.g., Barlow, 1981) have proposed that 
statistically significant outcome measures typically used in research settings may have little practical significance for the patients. Moreover, some have noted that there is a rift between research outcomes and clinically relevant patient care (Tunis, Stryer, \& Clancy, 2003). There may be little concordance between standard clinical measures, and clinically relevant improvement (Glasgow, Magid, Beck, Ritzwoller, \& Estabrooks, 2005).

In addition to measures of symptom severity, some advocate for collecting a broad range of outcome measures to determine the clinical relevance of a treatment. Some authors have called for a "patient-centered approach," that relies on practical and relevant outcome measures such as quality of life, functional outcome, and satisfaction (Glasgow et al., 2005; Tunis et al., 2003). The importance of examining multiple response modes, including motoric, cognitive, and physiological responses, has also been stressed for decades in the assessment literature (Eid \& Diener, 2006; Hayes and O’Brien, 2000; Lang, 1968). This is important, in part, because of the discordance between response modes, which is especially salient in anxiety disorders (e.g., Glass \& Arnkoff, 1989; Lang, 1968). For example, a person's cognitive response to a feared stimulus (e.g., "I feel scared.”) may not necessarily match his or her physiological response (e.g., increased levels of salivary cortisol, increased blood pressure). Similarly, self-reported fear may not match a person's actions or physiological response. Such findings also suggest variability in patterns of response to arousing stimuli across individuals (Lacey, Bateman, \& Van Lehn, 1953). Thus, some outcome measures will more accurately reflect an individual's response to arousing stimuli than others. In summary, these findings reinforce the importance of examining treatment outcome comprehensively, and certainly beyond the usual measures of anxiety or global improvement in older adults. 


\section{Statement of the Problem}

Anxiety disorders are common among older adults, affecting up to $10.2 \%$ of older adults (Beekman et al., 1998). Generalized Anxiety Disorder (GAD) is the most common of the anxiety disorders among older adults, affecting $7.3 \%$ of those in the community (Beekman et al., 1998). However, GAD often goes underreported and undertreated in older adults (Harman et al., 2002), in part because of some unique challenges to diagnosis in this population (Lenze et al., 2000; Palmer et al., 1997). For example, older adults may present with different symptoms than younger adults (Christensen et al., 1999; Shapiro et al., 1999; Spar \& LaRue,1990). Further, frequent medical and psychiatric comorbidities may complicate the diagnostic picture due to overlap in symptoms (Lenze et al., 2000; Palmer et al., 1997). This under-detection is problematic because GAD is associated with poorer quality of life (Bourland et al., 2000; Porensky et al., 2009; Stanley et al., 200; Wetherell et al., 2004;), and worse perceptions of mental and physical health (Stanley et al., 2003) among older adults. Moreover, GAD may be associated with abnormal HPA-axis functioning, and thus elevated levels of cortisol, which may put older adults with GAD at risk for more health problems, including dementia (Beaudreau, S. \& O’Hara, R., 2008; Chaudieu et al., 2008; Mantella et al., 2008; Van Cauter et al., 1996). Researchers have attempted to identify potential predictors of treatment outcome, including demographic, psychiatric, and treatment variables (See Tables 1 and 2 for a summary). The identification of patient variables that can predict treatment outcome in older adults with GAD could have significant clinical and research implications. For example, knowledge of symptom presentations that predict positive treatment outcomes with particular treatments could guide providers when making treatment choices. 
Because older adults may present with different symptoms of anxiety than younger adults (Christensen et al., 1999; Shapiro et al., 1999; Spar \& LaRue,1990), the symptoms that predict treatment success for them may also differ from those that predict success in younger adults. Only one study has examined the predictive value of baseline symptoms and treatment variables for treatment outcome in a sample of older adults. Using a Reliable Change Index, or RCI, for three measures (GAD severity rating using Anxiety Disorders Interview Schedule for Adults (ADIS-IV; Brown, DiNardo, \& Barlow, 1994) ratings, HAMA scores, and PSWQ scores), Wetherell and colleagues found that better outcomes were associated with higher GAD severity at baseline, presence of Axis I comorbidity, and more frequent homework (Wetherell et al., 2005). However, this study relied on total scores from their clinical measures and various treatment variables, rather than specific presenting symptoms, to predict outcome. Although helpful, such studies do not provide a fine-grained analysis of the presenting symptoms that are associated with positive outcomes.

Because older adults may present with different symptoms of anxiety than their younger counterparts (Christensen et al., 1999; Shapiro et al., 1999) it may be useful to take a broader look at the symptoms that predict response, beyond the DSM criteria. For example, no studies have examined the predictive value of somatic manifestations of anxiety (e.g., cardiovascular symptoms and gastrointestinal distress) on treatment outcome.

For those older adults whose anxiety disorders are identified, effective pharmacological (Lenze et al., 2009; Sheikh \& Cassidy, 2000) and psychosocial (see Ayers et al., 2007 for a review) treatments are available. Though there have been several promising treatment studies, both examining pharmacological and psychosocial treatments, there is no consistently used treatment outcome measure and no consensus on what outcome measure should be used. Some 
of the studies discussed above defined treatment outcome as a reduction of worry (e.g., Stanley et al., 1996), while others defined response as a reduction in presenting symptoms of anxiety (e.g., Lenze et al., 2005). Still others defined response as reduction in GAD severity (e.g., Mohlman et al., 2003), improved quality of life (e.g., Lenze et al., 2009; Stanley et al., 1996), or overall global improvement (e.g., Lenze et al., 2009). Most studies examined some combination of these response measures, but focused outcome on one measure of response. In addition to traditional outcome measures of symptom severity and morbidity, some have advocated the use of multiple measures of outcome across different domains (Lang, 1968), and the use of measures that have practical clinical significance (e.g., Glasgow et al., 2005; Tunis et al., 2003). Little research has examined the ways in which treatment response varies according to how outcome is measured, and whether a positive outcome in one domain is associated with a positive outcome in others (e.g., is a reduction in worry associated with an improvement in quality of life?). It is possible the people with different constellations of presenting symptoms respond to treatment in different ways. However, most researchers haven't specifically identified who improves from what treatment, and in which ways they benefit.

In sum, researchers have identified predictors of treatment response among younger adults. However, only one study has examined predictors in older adults (Wetherell et al., 2005), and only one study has examined the predictive power of specific symptom presentations, beyond DSM criteria, in a sample of young adults (Pollack et al., 2003). We lack a clear picture of the value of the manifestations of anxiety, beyond the symptoms represented by the DSM-IV criteria, for predicting treatment response with older adults. Moreover, the value of these predictors appears to vary depending upon how researchers have defined treatment response in each of the outcome studies. It is possible that the course of treatment, and treatment 
effectiveness may vary according to how response is measured. Previous studies typically have not employed outcome measures that examine change across different response modes.

The present study was designed to address two objectives. The first objective was to identify presenting symptoms that differentiate older adults with GAD from those without GAD. The second objective was to determine which of those symptoms were predictive of treatment response, and how the symptoms predicted response for each of several different outcome measures. To address the first objective, the current study examined the value of baseline levels of common presenting symptoms of GAD, as measured by SIGH-A items, in their ability to discriminate older adults with GAD from older adults without GAD. Using the baseline levels of the symptoms that differentiated older adults with GAD from those without, the current study addressed the second objective by examining the ability of these symptoms to predict treatment outcome in a sample of older adults with GAD receiving escitalopram. The SIGH-A is comprised of 14 clusters of common presenting symptoms (anxious mood, tension, fears, insomnia, concentration, depressed mood, somatic muscular, somatic sensory, cardiovascular, respiratory, gastro-intestinal, genitor-urinary, autonomic, and behavior). The current study examined the extent to which the baseline levels of symptom clusters that differentiated individuals with GAD from those without predicted successful treatment outcome as measured by the PSWQ scores, SF-36 quality of life scores (Mental and Physical components), global improvement scores, and cortisol levels.

Method

\section{Participants}


One hundred and seventy-seven participants, aged 60 and older, were recruited between the years 2004 and 2008 for the parent study: a double-blind placebo controlled medication treatment study of the efficacy of escitalopram for the treatment of generalized anxiety disorder in older adults at the University of Pittsburgh Medical Center (Lenze et al., 2009). Participants were recruited from primary care clinics, specialty medical care clinics, mental health clinics, and community advertisement. Most of the participants were Caucasian (82\%), and female (67.2\%). Nearly one-quarter $(24.8 \%)$ of the participants had a current diagnosis of a depressive disorder, and $20.9 \%$ had a diagnosis of a comorbid anxiety disorder, other than GAD. All participants received one hundred dollars and study medication at no cost.

Each participant was assessed using the Structured Clinical Interview for DSM Disorders (SCID; First, Spitzer, Gibbon, \& Williams, 2002), and met criteria for a principal diagnosis of GAD, according to the Diagnostic and Statistical Manual of Mental Disorders, Fourth Edition (DSM-IV; APA, 1994). Each participant scored 17 or higher on the SIGH-A, indicating clinically significant levels of anxiety. Participants with active suicidal ideation, drug or alcohol abuse or dependence in the previous 6 months, a lifetime prevalence of psychosis or bipolar disorder, dementia, medical instability, or current psychotherapy, antidepressant, or anxiolytic treatment were excluded from the study (Lenze et al., 2009).

To examine variables that predict treatment response to escitalopram, a subset of participants was examined. Of the 177 participants who were randomized into the parent study, 70 participants were randomized to escitalopram and completed 12 weeks of blinded treatment. Because researchers for the parent study did not begin collecting salivary cortisol samples at the outset of the study, salivary cortisol data are not available for some participants. Of those 70 
participants who were randomized to escitalopram and completed 12 weeks of treatment, only 23 collected both baseline and week 12 samples of salivary cortisol.

Forty-one control participants were also recruited. Control participants had no SCID diagnosis. As with participants in the active group, control participants with active suicidal ideation, a lifetime prevalence of dementia, medical instability, or current psychotherapy, antidepressant, or anxiolytic treatment were excluded from the study.

\section{Materials}

Structured Interview Guide for the Hamilton Anxiety Rating Scale (SIGH-A; Shear et al., 2001). The Structured Interview Guide for the Hamilton Anxiety Rating Scale, or SIGH-A, is a 14-item structured interview based on the Hamilton Rating Scale (HAMA; Hamilton, 1959) that is used to measure anxiety (See Appendix A). The items cover a range of psychological, physiological, and behavioral manifestations of anxiety. Each item is rated on a scale from 0 to 4, with higher scores indicating increased duration, distress, and impairment. The HAMA is widely used to assess anxiety and has been validated for use with older adults (Beck, Stanley, \& Zebb, 1999). The HAMA has been shown to demonstrate good internal consistency $(\alpha=.77)$ among participants with GAD (Beck et al., 1999). Further, it had good discriminant validity, correctly classifying $98 \%$ of older adults with GAD, and $100 \%$ of older adult controls (Beck et al., 1999). The SIGH-A was developed by Shear and colleagues (2001) from the HAMA. The SIGH-A offers more detailed instructions for administration, and clearer anchor points for rating. Though not tested in older adults, the SIGH-A demonstrates good internal consistency when tested over two days in a sample of adults with $\operatorname{GAD}(\alpha=.79$; Shear et al., 2001). SIGH-A scores were also correlated with HAMA scores in a sample of adults aged 18 and older with GAD ( $r=0.70$ on day one, $r=0.72$ on day two) (Shear et al., 2001). The SIGH-A is organized 
into 14 clusters of symptoms: anxious mood, tension, fears, insomnia, concentration, depressed mood, somatic muscular, somatic sensory, cardiovascular, respiratory, gastro-intestinal, genitorurinary, autonomic, and behavior. Each cluster has a structured list of questions about various symptoms that fall under the broader category of the cluster. The interviewer inquires about the presence of each symptom, then rates the whole cluster on a scale from 0-4 based on the frequency and severity of the collection of symptoms (See Appendix A). The current study recorded the "yes/ no" dichotomous response to each symptom under each category, to be able to have a more detailed picture of the experience of anxiety in older adults.

Penn State Worry Questionnaire (PSWQ; Meyer et al., 1990). The PSWQ is a 16-item self-report questionnaire used to assess worry (See Appendix B). Each item is rated on a scale from 1 (not at all typical) to 5 (very typical). Higher scores indicate higher levels of worry. In a sample of older adults, moderate correlations were observed between the PSWQ and other measures of anxiety, including the Worry Scale (WS; $\mathrm{r}=.54, \mathrm{p}<.01$ ), the original Fear Questionnaire (FQ-A; $\mathrm{r}=.36$ ), and the modified Fear Questionnaire (FQ-F; r=.30. , supporting convergent validity (Stanley, Novy, Bourland, Beck, \& Averill, 2001). Test-retest reliability of the PSWQ among older adults has been shown to be moderate ( $r=.54$; Stanley et al., 2001).

Short Form 36 Health Survey Questionnaire (SF-36; Ware \& Sherbourne, 1992). The SF-36 is a 36-item self-report measure of health that measures health across 8 dimensions: physical functioning, social functioning, role limitations, mental health, vitality, pain, general health perception, and health change (see Appendix C). High scores indicate better healthrelated quality of life and functioning. The SF-36 demonstrated good adequate internal consistency on each of the 8 dimensions. SF-36 scores can be divided into two subscales. One is referred to as the "mental component" (SF-36 MC) and the other is referred to as the "physical 
component" (SF-36 PC). Cronbach's $\alpha$ ranged from .73 (social functioning) to .96 (role limitations and vitality) (Brazier et al., 1992).

Clinical Global Impression- Improvement scale (CGI-I; Guy, 1976). The CGI-I is a commonly used single item index used to quantify improvement or worsening of anxiety symptoms since baseline (See Appendix D). Participants are rated on a scale from 1 to 7, where $1=$ very much improved, and $7=$ very much worse, based on a synthesis of patient's subjective report of improvement, change in measures, and clinician's report. In a study of the clinical utility of CGI-I scores for evaluating psychiatric in-patients with a wide range of diagnoses, investigators found CGI-I scores were found to be correlated with other measures of clinical change ( $\mathrm{r}=.71$ ), indicating clinical utility and sensitivity to change (Berk et al., 2008). Zaider, Heimberg, Fresco, Schneier, and Lebowitz (2003) also found evidence supporting the validity of the CGI-I as a meaningful measure of improvement in a sample of adults receiving treatment for social anxiety. Zaider and colleagues (2003) found CGI-I scores to be correlated with both selfreport and clinician rated measures of social anxiety, disability, and quality of life at post treatment.

Salivary Cortisol- Baseline samples of salivary cortisol were taken 6 times a day over 2 days before participants entered treatment because cortisol levels fluctuate throughout the day. Follow up samples were taken 6 times a day over the 2 days before participants' week 12 visits. Samples were taken immediately at wakening, 30 minutes after wakening, noon, 3:00 pm, 6:00 pm, and before bedtime. Participants were instructed to not eat or drink anything other than water for half an hour before taking a sample and to refrain from drinking alcohol for two days prior to taking samples, and during the sampling period. Participants tracked the exact time at which they took each sample on a diary form. Samples were stored at $-80 \mathrm{C}$ until they 
centrifugation. Samples were centrifuged using an enzyme immunoassay kit (Salimetrics, State College, PA). Cortisol levels and diurnal cycles were plotted. Numerous studies have indicated that cortisol may be a biomarker for psychological distress in older adults (Luz et al., 2003; Ryff et al., 2006; Mantella et al., 2008).

\section{Procedure}

After participants were screened, those who were eligible were invited back for a baseline visit. Two days prior to the baseline visit, participants collected samples of salivary cortisol. At the baseline visit, participants completed measures of anxiety (the Structured Interview Guide for the Hamilton Anxiety Rating Scale; SIGH-A), worry (the Penn State Worry Questionnaire; PSWQ), and quality of life (the Short Form 36; SF-36) as part of a more extensive battery. Participants were randomly assigned to either a starting dose of $10 \mathrm{mg}$ of escitalopram, or a placebo.

Both participants and investigators were blinded to this assignment. Participants received weekly follow up assessments for the first 4 weeks, when they received another SIGH-A, a measurement of side-effects, and a rating of global improvement, based on both clinician and participant impressions of change since baseline. After 4 weeks, participants were eligible to receive an increased dose of escitalopram $(20 \mathrm{mg})$. All participants were eligible for a titrated dose, unless they received a CGI score of "much improved" or higher, and a 40\% or greater drop in SIGH-A score from baseline. Between week 4 and week 12, participants were assessed either in person or by phone every 2 weeks.

After 12 weeks, participants ended the blinded phase of the study, and were offered open label escitalopram for another 12 weeks. For two days before the week 12 visit, participants collected follow up samples of salivary cortisol. At the week 12 visit, participants completed 
follow up measures, including the SIGH-A, PSWQ, and SF-36, as part of a more extensive assessment battery. The current study examined data at baseline and week 12 in order to see how baseline variables predict change after a sufficient course of medication.

Results

Descriptive statistics were calculated for the demographic data from the group with a primary diagnosis of GAD and control participants (see Table 3). Descriptive statistics were also calculated for both participants with GAD and those without fir baseline levels of the outcome variables: PSWQ, SF-36 (mental and physical components), and salivary cortisol (see Table 4). Salivary cortisol levels were reported as an area under the curve value, and were calculated using the technique established in the literature (Mantella et al., 2008; Pruessner et al., 1997). Skew and kurtosis were within one standard score from zero for all outcome variables with the exception of the MOS-Physical Component, which had a z-score for kurtosis of -1.105 . The data were not transformed. For participants with GAD who were randomized to medication, paired sample t-tests were conducted to determine whether the outcome variables differed significantly at week 12 from baseline (See Table 5).

Baseline scores were significantly positively correlated with week 12 scores for the PSWQ, $r(68)=.80, p<.001$; the SF-36 MC, $r(68)=.52, p<.001$; and the SF-36 PC, $r(68)=$ $.79, p<.001($ See Table 6). However, these scores are not independent. There were no significant correlations between baseline AUC levels of salivary cortisol or week 12 AUC levels and any other outcome variables. Because the CGI-I score assesses improvement from baseline, no baseline CGI-I scores were collected. PSWQ week 12 scores were significantly correlated 
with all outcome measures, with the exception of salivary cortisol. Neither baseline nor week 12 levels of salivary cortisol were correlated with any other outcome variable.

A series of exploratory t-tests were performed to examine differences between the total group of those with a primary diagnosis of GAD ( $\mathrm{n}=177)$ and the control group on the 14 individual cluster scores of the SIGH-A measures. All items differed significantly between the two groups (see Table 78).

Hypothesis Testing

The first objective was to determine which SIGH-A cluster symptoms were best at differentiating older adults with GAD from those without GAD. To test this objective, a discriminant function analysis was performed to determine which cluster item baseline scores classified participants according to group membership. Baseline scores on each of the 14 symptom clusters of the SIGH-A were entered into the equation, The discriminant analysis revealed one discriminant function, which included the "Anxious Mood" and "Tension" items from the SIGH-A, and correctly classified $100 \%$ of the participants as either "GAD" or "no GAD” (See Table 8), canonical $\mathrm{R}^{2}=.95\left(\lambda=0.1, \chi^{2}(2), \mathrm{p}<.01\right)$.

A correlation matrix was constructed to examine the relations between the predictor variables ("Anxious Mood" and "Tension" items) and baseline and week 12 scores on each of the outcome measures: PSWQ, SF-36 MC, SF-36 PC, CGI-I, and AUC of salivary cortisol (see Table 6). The "Anxious Mood" item was significantly correlated with PSWQ scores at both baseline, $r(68)=.32, p<.001$, and week $12, r(68)=.24, p<.01$, and it was inversely correlated with MOS MC scores at week 12, $r(68)=-.24, p<.01$.

The second objective was to determine how well the variables that best discriminate between older adults with GAD and those without GAD predict improvement across a variety of 
measures. To test the second objective, the "Anxious Mood" and "Tension" items were retained for use in a linear regression to predict which symptom presentations predicted response across outcome measures assessing different domains of treatment response (see Table 9). Five hierarchical regression analyses with forward variable entry were completed, using different outcome measures as the dependent variable for each analysis: worry level (as measured by the change in PSWQ score from baseline to week 12 of treatment), quality of life (as measured by the SF-36 Mental and Physical components change in from baseline to week 12 of treatment), clinical global improvement (as measured by the CGI-I), and salivary cortisol levels (as measured by change in salivary cortisol levels from baseline to week 12). To account for baseline symptoms, baseline scores of the PSWQ, the SF-36 MC and PC, and salivary cortisol were entered into the first step of their respective regression analyses. Baseline "Anxious Mood" and "Tension" SIGH-A item scores were added in the second step, using the backward entry method. Because the CGI-I measures change from baseline, it was not necessary to account for baseline scores when examining the predictive value of the SIGH-A items on week 12 CGI-I score. To perform a regression analysis for CGI-I, both the "Anxious Mood" and "Tension" items were added to the model using backwards entry.

Two models were shown to predict week 12 PSWQ scores proved to be significant (See Table 9). In the first model, only baseline PSWQ scores were included, $\beta=.79, t(66)=$ $10.80, p<.001$. Baseline PSWQ scores accounted for a significant amount of the variance in week 12 scores, $R^{2}=.65, F(1,64)=116.70, p<.01$. The "Anxious Mood" nor the "Tension" items of the SIGH-A at baseline were added to the second model, but this equation did not account for a significant amount of variance beyond that accounted for by baseline PSWQ scores. 
There were also two models shown to predict week 12 SF-36 MC scores. The first model only included baseline SF-36 MC scores, and it was significant, $\beta=.52, t(66)=4.96, p<.001$. Baseline SF-36 MC scores predicted $28 \%$ of the variance in week 12 scores, $\Delta R^{2}=.28, F(1,64)$ $=24.61, p<.001$. In the second model, the "Anxious Mood" and "Tension" items were added, but they did not account for a significant amount of variance beyond baseline scores.

A regression analysis was also conducted to see which variables predicted week 12 SF36 PC scores. Again, two models were computed. In the first model, only SF-36 PC scores were added, $\beta=.79, t(66)=10.31, p<.001$. Baseline SF-36 PC scores accounted for $62 \%$ of the variance in week 12 scores, $R^{2}=.62, F(1,64)=106.38, p<.001$. In the second model, but the "Anxious Mood" and "Tension" SIGH-A items were added to the equation, but they did not account for significant variance beyond the baseline levels.

Two models were tested for their ability to predict week 12 AUC measurements of salivary cortisol, but neither was significant. The first model only included baseline levels of AUC, $\beta=.30, t(66)=1.39, p=.18$. Baseline AUC measurements accounted for $9 \%$ of the variance in week 12 scores, $R^{2}=.09, F(1,64)=1.94, p=.18$. The second model included the “Anxious Mood" and "Tension" items, but still did not account for a significant amount of vaiance, $R^{2}=.12, F(1,64)=.85, p=.49$.

Similarly, the model were tested for its ability to predict week 12 CGI-I scores, was not significant. The "Anxious Mood" and "Tension" items predicted only $0.8 \%$ of the variance in CGI-I score at week $12, R^{2}=.008, F(1,64)=0.26, p=.78 . \quad$ Residualized change scores were calculated for the PSWQ, the SF-36 MC and PC, and AUC for salivary cortisol as an alternative approach to characterizing outcome. Residualized change scores are sometimes used as a way to measure change that accounts for both the size and the reliability of the change (MacKinnon, 
2008). Using the residualized change scores as criterion variables, the "Anxious Mood" and

"Tension" items were entered into a regression analysis using the forward entry method to determine whether they could predict residualized change scores for the measures discussed above. No models were significant.

\section{Discussion}

The current study aimed to determine the extent to which baseline SIGH-A symptom clusters could predict treatment response across a variety of domains. The investigator chose to examine the predictive value of symptoms clusters that best differentiated older adults with GAD from those without. Though there has been debate about the ways in which anxiety differs in older adults (Christensen et al., 1999; Spar \& LaRue, 1990), in the current study, anxious mood and tension best differentiated between groups of older adults with GAD and those without. Older adults with GAD had higher levels of each of the symptom clusters measuring physical symptoms of anxiety than those without GAD, but anxious mood and tension seemed to be key symptoms for distinguishing between the two groups. These findings partially replicate the findings by Wetherell and colleagues (2003). Wetherell and colleagues examined the diagnostic symptoms of GAD derived from the ADIS. Using a discriminant function analysis, they found that distress and impairment, frequency and uncontrollability of worry, muscle tension, and sleep disturbances differentiated the groups, suggesting that they may be key symptoms of late-life GAD. Both the current study, and the study conducted by Wetherell and colleagues found that worry and tension differentiated between groups of older adults with GAD and those without. However, the Wetherell study examined different characterizations of worry, specifically frequency and uncontrollability, and distress and impairment. Moreover, they found that sleep disturbances also differentiated between the groups. The current study derived symptom clusters 
for the analysis from the SIGH-A, while Wetherell and colleagues derived symptom clusters from the ADIS. Though there is some overlap in the construct measured, the manner in which the questions were asked, and the range of symptoms measured differed between the current study and the study conducted by Wetherell and colleagues. The SIGH-A covers a broader range of symptoms, including both diagnostic criteria, and other common anxiety symptoms. These differences in measurement could account for the partial differences in results.

The results of the discriminant function analysis support the idea that worry and tension are the hallmark symptoms of GAD in older adults. Moreover, the finding that "Anxious Mood" and "Tension" were best able to classify older adults with GAD falls into line with the proposed DSM-V criteria for GAD, which proposes that we put more emphasis of excessive worry and tension for the diagnosis of GAD (APA, 2010). Considering the conflicting findings in the literature as to whether older adults present with more somatic symptoms, this shift could simplify diagnosis of GAD in older adults.

The finding that week 12 PSWQ scores, which reflect worry, were significantly correlated with global improvement and both physical and mental components of a measure of quality of life, provides further support for a greater focus on worry and tension for assessing GAD. Week 12 PSWQ scores were significantly correlated with all outcome measures except salivary cortisol, adding support for convergent validity, and indicating the the PSWQ may be a good measure of GAD in older adults.

Previous researchers have found significant correlations between severity of GAD as measured by the PSWQ, and the GADSS to be positively correlated with levels of salivary cortisol (Mantella et al., 2008). It is unclear why the levels of salivary cortisol were not significantly correlated with any other outcome measure in this sample. It is also unclear why 
the model used to predict week 12 levels of salivary cortisol was non-significant. It is possible that those who collected samples of salivary cortisol were qualitatively different than those who did not, though t-tests revealed that the group that collected both baseline and week 12 samples of salivary cortisol did not differ significantly according to age, sex, race, or years of education. However, because only a subsample of older adults collected salivary cortisol, the current study did not have enough power to test this outcome measure.

Contrary to our predictions, scores on the "Anxious Mood" and "Tension" items of the SIGH-A at baseline did not significantly predict outcome in any domain. Ratings of baseline levels of anxious mood or somatic tension did not significantly predict scores on outcome measures across different domains of response. It is possible that the "Anxious Mood" and "Tension" items measured constructs that are semantically similar to the outcome variables. The “Anxious Mood" items assess for frequency, severity, and impairment as a result of anxiety or worry in the past week. There could be overlap in the construct that the "Anxious Mood" item and the PSWQ scale measured, as evidenced by the significant correlation between them. The SF-36 MC and the "Anxious Mood" and "Tension" items were also correlated, indicating that the constructs measured may overlap. As a result, it is possible that the SIGH-A items scores did not account for a significant amount of variance beyond baseline measures, because they were measuring similar things.

Moreover, it is also possible that the fact that all participants met SCID criteria for GAD may have narrowed the range of presenting symptoms at baseline, and the severity of symptoms at baseline. In order to meet diagnostic criteria for GAD, one must endorse excessive, distressing and difficult to control worry on more days than not. All enrolled participants endorsed this type of worry in order to be eligible for the study. Scores on the "Anxious Mood" 
item on the SIGH-A ranges from 0-4. However, those who meet full criteria for GAD would likely automatically receive a score of 3 or 4 on the "Anxious Mood" item because of the frequency and level of distress required to meet diagnostic criteria. Possibly limited baseline variability in the sample on the "Anxious Mood" item could result in the lack of ability to predict outcome on measures that have wider ranges of response.

Further, baseline and week 12 scores on outcomes measures tended to be highly correlated (see Table 7), and thus accounted for much of the variability in outcome. However, baseline scores on the PSWQ were very strong predictors of outcome at 12 weeks on the PSWQ. Similarly, baseline scores on the SF-36 PC were very stong predictors of week 12 SF-36 PC score. Baseline scores on the SF-36 MC were also strong predictors of week 12 SF-36 MC. These findings indicate that higher scores on the PSWQ, the SF-36 PC, and the SF-36 MC at baseline are associated with higher scores on each respective measure after 12 weeks of pharmacotherapy. It is difficult to make direct comparisons with other studies examining predictive value of symptoms because no other studies have used SIGH-A symptom clusters to predict treatment outcome. However, we can draw some tentative comparisons to the literature. The present findings may support the findings of Haby and colleagues (2006), who found that greater severity of symptoms at baseline predicted poorer outcomes on measures of anxiety symptoms and health related quality of life. However, they conflict with the findings of Wetherell and colleagues (2005), who reported that greater severity of GAD, as measured by the ADIS at baseline, predicted better outcomes on a reliable change index. This calls into question whether results obtained through different methods of measurement, and defined in different terms, can be generalized to the current study. The discrepancy could be due, in part, to differences in defining "improvement" across treatment studies. The current study defined 
improvement as a multifaceted change that took place across multiple domains. Improvement can be a reduction in worry, improvement in quality of life, global improvement, or reduction in levels of salivary cortisol. However, other treatment studies have used different definitions of improvement. Again, because different predictors and outcome measures and were used in the literature, comparisons to existing studies should be interpreted with caution.

\section{Limitations}

The current study was limited by the characteristics of the sample. It examined a population of treatment-seeking older adults who enrolled in a pharmacotherapy study. It is possible that these results may not generalize to other populations of older adults with GAD. Moreover, the study sample may be qualitatively different as a result of the inclusion and exclusion criteria (e.g., all those with substance abuse in the past 6 months were excluded) used for study eligibility. Further, a smaller sample of older adults with GAD collected salivary cortisol sample. It is possible that those who collected the samples were qualitatively different than those who did not. The small sample size may have resulted in insufficient power, limiting the findings.

Several methodological factors may limit the findings of the current study. This study aimed to determine which symptoms were best at differentiating older adults with GAD from those without GAD, and to see how those symptoms predicted response across different outcome measures. However, in doing so, the investigators only examined the predictive value of the symptoms that were best at differentiating older adults with GAD from those without and did not examine the predictive value of other presenting symptoms. Though examining the symptoms that are best at differentiating the two groups may make the results more clinically accessible, it is possible that symptoms that were less successful at differentiating between older adults might 
be better predictors of outcome. Moreover, the predictor variables used were single item responses, with a limited range. Because of the limitations of using a single-item predictor variable with limited range, researchers might revisit the predictive value of anxious mood and tension using more comprehensive measures designed to assess the constructs, rather than singleitem scores.

The current study was also limited in its ability to measure change. There has been considerable controversy in the literature over the years regarding the most appropriate ways to measure change (e.g., Cronbach \& Furby, 1970). Rogosa, Brandt, and Zimowski (1982) outlined some of the difficulties in measuring change. They discussed the established finding that initial and outcome values tend to be correlated when measures are reliable. These correlations can make assessing for clinically significant change difficult. A conservative approach to measuring change was taken in the present study, but it may have missed clinically significant change that was masked because of high correlations between baseline and outcome scores. Moreover, without a control comparison, the current study could not account for the waxing and waning of anxiety over the 12 weeks of treatment. The current study was also limited in its ability to assess for treatment compliance. The investigators did not account for whether participants were taking their medication as prescribed when assessing outcome.

Future Directions and Conclusions

The current study found that anxious mood and tension were the most salient symptoms in differentiating older adults with GAD from those without. This suggests that measures used to assess GAD in late life should focus on tension and anxious mood. The PSWQ was significantly correlated with other measures of outcome, and seems to be an appropriate assessment of late life GAD. These results are in line with the proposed criteria for the DSM-V. Though neither 
baseline levels of anxious mood nor tension significantly predicted outcome in a variety of measures, baseline scores on the PSWQ, SF-36 MC and SF-36 PC were strong predictors of week 12 scores, with higher levels at baseline being associated with higher levels at week 12 on all measures. Though these findings did not support our hypothesis that presenting symptoms could predict outcome, they still inform expectations for treatment.

Based on these findings, researchers might consider using more comprehensive measures of anxious mood and tension to examine their predictive value on outcome. Researchers might also explore the predictive ability of other symptom presentations, including the other 12 symptom clusters from the SIGH-A.

Further, it would be interesting to examine longer-term outcomes. Do certain symptoms, or baseline severity measures, predict stable improvement? Do other symptoms or severity measures predict relapse? By learning the answers to these questions, providers could tailor treatments for GAD to individuals who are likely to receive the most benefit. 


\section{References}

American Psychological Association (1994). Diagnostic and Statistical Manual of Mental Disorders, DSM-IV-TR (Fourth ed.). Washington, DC: American Psychiatric Association (APA).

American Psychological Association (2010). DSM-5 development. Retrieved March 15, 2010 from http://www.dsm5.org/Pages/Default.aspx

Ayers, C. R., Sorrell, J. T., Thorp, S. R. \& Wetherell, J. L. (2007). Evidence-based psychological treatments for late-life anxiety. Psychology and Aging, 22(1), 8-17.

Barlow, D. H. (1981). On the relation of clinical research to clinical practice: Current issues, new directions. Journal of Consulting, 49, 147-155.

Beaudreau, S. \& O'Hara, R. (2008). Late life anxiety and cognitive impairment: A review. American Journal of Geriatric Psychiatry, 16, 790-803.

Beck, J. G., Stanley, M. A., \& Zebb, B. J. (1999). Effectiveness of the Hamilton Anxiety Rating Scale with older generalized anxiety disorder patients. Journal of Clinical Geropsychology, 5, 281-290.

Beekman A. T., Bremmer, M. A., Deeg, D. J., van Balkom, A. J., Smit, J. H., de Beurs, E., Van Dyke, R., \& van Tilburg, W. (1998). Anxiety disorders in later life: a report from the longitudinal aging study Amsterdam. International Journal of Geriatric Psychiatry, 13, 717- 726.

Berk, M., Ng, F., Dodd, S., Callaly, T., Campbell, S., Bernardo, M., \& Trauer, T. (2008). The validity of the CGI severity and improvement scales as measures of clinical effectiveness suitable for routine clinical use. Journal of Evaluation in Clinical Practice, 14, 979-983. 
Bourland, S. L., Stanley, M. A., Snyder, A. G., et al. (2000). Quality of life in older adults with generalized anxiety disorder. Aging and Mental Health, 4, 315-23.

Brazier, J. E., Harper, R., Jones, N. M., O’Cathain, A., Thomas, K. J., Usherwood, T., \& Westlake, L. (1992). Validating the SF-36 health survey questionnaire: New outcome measure for primary care. British Medical Journal, 305, 160-164.

Brenes, G. A., Guralnik, J. M., Williamson, J., Fried, L. P., Simpson, C., Simonsick, E. M., \& Pennix, B. W. J. H. (2005). The influence of anxiety in the progression of disability. Journal of the American Geriatrics Society, 53, 34-39.

Brown, B. A, \& Barlow, D. H. (2009). A proposal for a dimensional classification system based on the shared features of the DSM-IV anxiety and mood disorders: Implications for assessment and treatment. Psychological Assessment, 21, 256-271.

Chaudieu, I., Beluche, I., Norton, J., Boulenger, J. P., Ritchie, K., \& Ancelin, M. L. (2008). Abnormal reactions to environmental stress in elderly persons with anxiety disorders: Evidence from a population study of diurnal cortisol changes, Journal of Affective Disorders, 106, 307-313.

Christensen, H., Jorm, A. F., Mackinnon, A. J., Korten, A. E., Jacomb, P. A., Henderson, A. S., \& Rodgers, B. (1999). Age differences in depression and anxiety symptoms: A structural equation modeling analysis of data from a general population sample. Psychological Medicine, 29, 325-339.

Cronbach, L. J., \& Furby, L. (1970). How should we measure "change"- or should we? Psychological Bulletin, 74, 68-80. 
de Beurs, E., Beekman, A. T., van Balkom, A. J., Deeg, D. J., van Dyck, R., \& van Tilburg, W. (1999). Consequences of anxiety in older persons: Its effect on disability, well-being and use of health services. Psychological Medicine, 29(3), 583-93.

DeMartinis, N., Rynn, M., Rickels, K., \& Mandos, L. (2000). Prior benzodiazepine use and buspirone response in the treatment of generalized anxiety disorder. Journal of Clinical Psychiatry, 61, 91-94.

Durham, R. C., Allan, T., \& Hackett, C. A. (1997). On predicting improvement and relapse in generalized anxiety disorder following psychotherapy. British Journal of Clinical Psychology, 36(1), 101-119.

Eid, M., \& Diener, E. (Eds.) (2006). Handbook of multimethod measurement in psychology. Washington, DC: American Psychological Association.

Ferrari, E., Magri, F., Dori, D., Migliorati, G., Nescis, T., Molla, G., Fioravanti, M., \& Bruno Solerte, S. (1995). Neuroendocrine correlates of the aging brain in humans, Neuroendocrinology, 61, 464-470.

First, M. B., Spitzer, R. L., Gibbon, M., \& Williams, J. B. W. (2002). Structured Clinical Interview for DSM-IV-TR Axis I Disorders, Research Version, Non-patient Edition. (SCID-I/NP) New York: Biometrics Research, New York State Psychiatric Institute.

Glasgow, R. E., Magid, D. J., Beck, A., Ritzwoller, D., \& Estabrooks, P. (2005). Practical clinical trials for translating research to practice: Design and measurement recommendations. Medical Care, 43, 551-557.

Glass, C. R., \& Arnkoff, D. B. (1989). Behavioral assessment of social anxiety and social phobia. Clinical Psychology Review, 9, 75-90. 
Goodman, W. K., Bose, A., \& Wang, Q. (2005). Treatment of generalized anxiety disorder with escitalopram: Pooled results from double_-blind placebo controlled studies. Journal of Affective Disorders, 87, 161-167.

Guy, W. (1976). NCDEU Assessment Manual for Psychopharmacology, rev. edn. US Department of Health, Education, and Welfare (ADM) 76-338. Rockville, MD. National Institute of Mental Health, pp. 218-222.

Haby, M. M., Donnelly, M., Corry, J., \& Vos, T. (2006). Cognitive behavioural therapy for depression, panic disorder and generalized anxiety disorder: a meta-regression of factors that may predict outcome. Australian and New Zealand Journal of Psychiatry, 40, 9-19.

Hamilton, M. (1959). The assessment of anxiety states by rating. British Journal of Medical Psychology, 32, 50-55.

Hansen, A. M., Garde, A. H., \& Persson, R. (2008). Sources of biological and methodological variation in salivary cortisol and their impact on measurement among healthy adults: A review. The Scandinavian Journal of Clinical \& Laboratory Investigation, 68, 448-458.

Harman, J. S., Rollman, B. L., Hanusa, B. H., Lenze, E. J., \& Shear, M. K. (2002). Physician office visits of adults for anxiety disorders in the United States: 1985-1998. Journal of General Internal Medicine, 17, 165-172.

Hayes, S. \& O’Brien, W. H. (Eds.)(2000). Principles and practice of behavioral assessment, New York, NY: Plenum Publishing Corporation.

Katz, I. R., Reynolds, C. F. III, Alexopoulos, G. S., \& Hackett, D. (2002). Venlafaxine ER as a treatment for generalized anxiety disorder in older adults: Pooled analysis of five randomized placebo-controlled clinical trials. Journal of the American Geriatric Society, $50,18-25$. 
Lacey, J. I., Bateman, D. E., \& Van Lehn, R. (1953). Autonomic response specificity. Psychosomatic Medicine, 15, 8-21.

Lang, P. J. (1968). Fear reduction and fear behavior: Problems in treating a construct. In Shlein (Ed.), Research in Psychotherapy (pp. 90- 102). Washington, DC: American Psychological Association.

Lecrubier, Y., Dolberg, O. T., Anderson, H. F., \& Weiller, E. (2008). Qualitative changes in symptomatology as an effect of treatment with escitalopram in generalized anxiety disorder and major depressive disorder. European Archives of Psychiatry and Clinical Neuroscience, 258, 171-178.

Lenze, E. J., Mulsant, B. H., Shear, M. K., Dew, M. A., Miller, M. D., Pollock, B. G., Houck, P., Tracey, B., \& Reynolds, C. F. (2005). Efficacy and tolerability of citalopram in the treatment of late-life anxiety disorders: Results from an 8-week randomized, placebocontrolled trial. American Journal of Psychiatry, 162, 146-150.

Lenze, E. J., Mulsant, B. H., Shear, M. K., Schulberg, H. C., Dew, M. A., Begley, A., Pollock, B. G., \& Reynolds, C. F. III (2000). Comorbid anxiety disorders in depressed elderly patients. American Journal of Psychiatry, 157, 722-728.

Lenze, E. J., Rogers, J. C., Martire, L. M., Mulsant, B. H., Rollman, B. L., Dew, M. A., Schulz, R., \& Reynolds, C. F. (2001). The association of late-life depression and anxiety with physical disability: A review of the literature and prospectus for future research. American Journal of Geriatric Psychiatry, 9, 113-135.

Lenze, E. J., Rollman, B. L., Shear, M. K., Dew, M. A., Pollock, B. G., Ciliberti, C., Costantino, M, Snyder, S., Shi, P., Spitznagel, E., Andreescu, C., Butters, M. A., \& Reynolds, C. F. 
(2009). Escitalopram for older adults with generalized anxiety disorder. Journal of the American Medical Association, 301, 295-303.

Luz, C., Dornelles, F., Preissler,T., Collaziol, D., da Cruz, I.M., \& Bauer, M. E. (2003). Impact of psychological and endocrine factors on cytokine production of healthy elderly people. Mechanisms of Aging and Development, 124, 887-895.

MacKinnon, D.P. (2008). Introduction to statistical mediation analysis, New York, NY: Taylor and Francis Group.

Mantella, R. C., Butters, M. A., Amico, J. A., Mazumdar, S., Rollman, B. L., Begley, A., Reynolds, C. F., \& Lenze, E. J. (2008). Salivary cortisol is associated with diagnosis and severity of late-life generalized anxiety disorder. Psychoneuroendocrinology, 33, 773781.

Meyer, T. J., Miller, M. L., Metzger, R. L., \& Borkovec, T. D. (1990). Development and validation of the Penn State Worry Questionnaire. Behavior Research and Therapy, 28, 487-495.

Mohlman, J., Gorenstein, E. E., Kleber, M., de Jesus, M., Gorman, J. M., \& Papp, L. A. (2003). Standard and enhanced cognitive-behavior therapy for late-life generalized anxiety disorder: Two pilot investigations. American Journal of Geriatric Psychiatry, 11, 24-32.

Palmer, B. W., Jeste, D. V., \& Sheikh, J. I. (1997). Anxiety disorders in the elderly: DSM-IV and other barriers to diagnosis and treatment. Journal of Affective Disorders. 46, 183-190.

Pollack, M. H., Meoni, P., Otto, M. W., \& Hackett, D. (2003). Predictors of outcome following venlafaxine extended-release treatment of DSM-IV generalized anxiety disorder: A pooled analysis of short- and long- term studies. Journal of Clinical Psychopharmacology, 23, 250-259. 
Porensky, E. K., Dew, M. A., Karp, J. F., Skidmore, E., Rollman, B. L., Shear, M. K., \& Lenze, E. J. (2009). The burden of late-life generalized anxiety disorder: Effects on disability, health-related quality of life, and healthcare utilization. American Journal of Geriatric Psychiatry, 17, 473-482.

Pruessner, J. C., Wolf, O. T., Hellhammer, D. H., Buske-Kirschbaum, A., von Auer, K., Jobst, S., Kaspers, F., \& Kirschbaum, C. (1997). Free cortisol levels after awakening: A reliable biological marker for the assessment of adrenocortical activity, Life Science, 61, 25392549.

Rogosa, D., Brandt, D., \& Zimowski, M. (1982). A growth curve approach to measurement of change. Quantitative Methods in Psychology, 92, 726-748.

Ryff, C. D., Love, G. D., Urry, H. L., Muller, D., Rosenkranz, M. A., Friedman, E. M., Davidson, R. J., \& Singer, B. (2006). Psychological well-being and ill-being: Do they have distinct or mirrored biological correlates?. Psychotherapy and Psychosomatics, 75, 85-95.

Rynn, M., Khalid-Khan, S., Garcia-Espana, J. F., Etmad, B., \& Rickels, K. (2006). Early response and 8-week treatment outcome in GAD. Depression and Anxiety, 23, 461-65.

Seivewright, H., Tyrer, P., \& Johnson, T. (1998). Prediction of outcome in neurotic disorder: A 5year prospective study. Psychological Medicine, 28, 1149-1157.

Shapiro, A. M., Roberts, J. E., \& Beck, J. G. (1999). Differentiating symptoms of anxiety and depression in older adults: Distinct cognitive and affective profiles?. Cognitive Therapy and Research, 23, 53-74.

Shear, M.K., Belnap, B.H., Mazumdar, S., Houck, P., \& Rollman, B.L. (2006). Generalized Anxiety Disorder Severity Scale (GADSS): A preliminary validation study. Depression and Anxiety, 23, 77-82. 
Shear, M. K., Vander Bilt, J., Rucci, P., Endicott, J., Lydiard, B., Otto, M. W., Pollack, M. H., Chandler, L., Williams, J., Ali, A., \& Frank, D. M. (2001). Reliability and validity of a structured interview guide for the Hamilton Anxiety rating scale (SIGH-A). Depression and Anxiety, 13, 166-178.

Sheikh, J. I. \& Cassidy, E. L. (2000). Treatment of anxiety disorders in the elderly: Issues and strategies. Journal of Anxiety Disorders, 14, 173-190.

Spar, J. E. \& LaRue, A., (1990). Geriatric Psychiatry, American Psychiatric Press, Washington, D.C.Spielberger, C., Gorsuch, R. \& Lushene, R. (1970). Manual for the State-Trait Anxiety Inventory Consulting Psychologists Press, Palo Alto, CA.

Stanley, M. A., Beck, J. G., \& Glassco, J. D. (1996). Treatment of generalized anxiety in older adults: A preliminary comparison of cognitive-behavioral and supportive approaches. Behavior Therapy, 27(4), 565-581.

Stanley, M. A., Diefenbach, G. J. \& Hopko, D. R. (2003). The nature of generalized anxiety in older primary care patients: Preliminary findings. Journal of Psychopathology and Behavioral Assessment, 25(4), 273-280.

Stanley, M., Novy, D., Bourland, S., Beck, J., \& Averill, P. (2001). Assessing older adults with generalized anxiety: A replication and extension. Behaviour Research and Therapy, $39(2), 221-235$.

Stein, D. J., Anderson, H. F., \& Goodman, W. K. (2005). Escitalopram for the treatment of GAD: Efficacy across different subgroups and outcomes. Annals of Clinical Psychiatry, 17(2), $71-75$ 
Tunis, S. R., Stryer, D. B., \& Clancy, C. M. (2003). Increasing the value of clinical research for decision making in clinical and health policy. Journal of the American Medical Association, 290, 1624-1632.

Tweed, D., Blazer, D., \& Ciarlo, J. (1992). Psychiatric epidemiology in elderly populations. In R.B. Wallace \& R.F. Woolson (Eds.) The Epidemiologic Study of the Elderly (pp. 213233). New York, NY: Oxford University Press

Van Cauter, E., Leproult, R., \& Kupfer, D. J. (1996). Effects of gender and age on the circadian rhythmicity of plasma cortisol. Journal of Clinical Endocrinology \& Metabolism, 81, 2468-2473.

Ware, J. E. \& Sherbourne, C. D. (1992). The MOS 36-item short-form health survey (SF-36): I. conceptual framework and item selection. Medical Care, 30(6), 473-483.

Wetherell, J. L., Hopko, D. R., Diefenbach, G. J., Averill, P. M., Beck, J. G., Craske, M. G., et al. (2005). Cognitive-behavioral therapy for late life generalized anxiety disorder: Who gets better?. Behavior Therapy, 36, 147-156.

Wetherell, J. L., Le Roux, H., \& Gatz, M. (2003). DSM-IV criteria for generalized anxiety disorder in older adults: Distinguishing the worried from the well. Psychology and Aging, $18(3), 622-627$.

Wetherell, J. L., Thorp, S. R., Patterson, T. L., Golshan, S., Jeste, D. V., \& Gatz, M. (2004). Quality of life in geriatric generalized anxiety disorder: A preliminary investigation. Journal of Psychiatric Research, 38, 305-312. 
Wisocki, P. A., Handen, B. \& Morse, C. K. (1986). The Worry Scale as a measure of anxiety among homebound and community active elderly. The Behavior Therapist, 5, 91-95.

Wittchen, H. U., Kessler, R.C., Beesdo, K., Krause, P., Höfler, M., \& Hoyer, J. (2002). Generalized anxiety and depression in primary care: prevalence, recognition, and management. Journal of Clinical Psychiatry, 63(8), 24-34.

Zaider, T. I., Heimberg, R. G., Fresco, M., Scneier, F. R., \& Liebowitz, M. R. (2003). Evaluation of the Clinical Global Impression Scale among individuals with social anxiety disorder. Psychological Medicine, 33, 611-622. 
Table 1

Predictor Variables and Treatment Outcome Measures for Pharmacological Interventions

\begin{tabular}{|c|c|c|c|c|}
\hline Researchers & $\mathrm{N}$ & Predictors & Non Predictors & $\begin{array}{l}\text { Outcome } \\
\text { Variable(s) }\end{array}$ \\
\hline $\begin{array}{l}\text { Pollack et al., } \\
2003\end{array}$ & $\begin{array}{l}\mathrm{N}=1,839 \\
\text { (pooled data) }\end{array}$ & $\begin{array}{l}\text { Sleep disturbance } \\
\text { predicted positive } \\
\text { outcomes in both } \\
\text { active treatment and } \\
\text { placebo groups. } \\
\text { Restlessness } \\
\text { predicted poorer } \\
\text { outcomes for both } \\
\text { groups. Trouble } \\
\text { concentrating and } \\
\text { history of substance } \\
\text { abuse predicted } \\
\text { better short-term } \\
\text { outcomes for } \\
\text { placebo group }\end{array}$ & $\begin{array}{l}\text { Age, duration } \\
\text { of episode, } \\
\text { benzodiazepine } \\
\text { use, history of } \\
\text { depression, } \\
\text { history of } \\
\text { panic disorder, } \\
\text { fatigability, } \\
\text { irritability, } \\
\text { muscle } \\
\text { tension, and } \\
\text { number of } \\
\text { GAD } \\
\text { diagnostic } \\
\text { criteria } \\
\text { endorsed }\end{array}$ & $\begin{array}{l}\text { Reduction in } \\
\text { HAM-A }\end{array}$ \\
\hline $\begin{array}{l}\text { DeMartinis, } \\
\text { Rynn, Rickels, \& } \\
\text { Mandos, } 2000\end{array}$ & $\mathrm{~N}=735$ & $\begin{array}{l}\text { Poorer prognosis } \\
\text { associated with } \\
\text { recent } \\
\text { benzodiazepine use }\end{array}$ & $\begin{array}{l}\text { Prior } \\
\text { benzodiazepine } \\
\text { use, no } \\
\text { benzodiazepine } \\
\text { use }\end{array}$ & $\begin{array}{l}\text { Reduction in } \\
\text { HAM-A } \\
\text { CGI } \\
\text { Patient attrition }\end{array}$ \\
\hline $\begin{array}{l}\text { Rynn, Khalid- } \\
\text { Khan, Garcia- } \\
\text { Espana, Estemad, } \\
\text { \& Rickels, } 2006\end{array}$ & $\mathrm{~N}=396$ & $\begin{array}{l}\text { Better outcomes } \\
\text { were associated } \\
\text { with early reduction } \\
\text { in HAMA (baseline } \\
\text { to weeks } 1 \text { and } 2 \text { ) }\end{array}$ & $* * *$ & $\begin{array}{l}\text { Reduction in } \\
\text { HAM-A at the } \\
\text { end of the trial } \\
\text { CGI }\end{array}$ \\
\hline
\end{tabular}


Table 2

Predictor Variables and Treatment Outcome Measures for Psychosocial Interventions

\begin{tabular}{|c|c|c|c|c|}
\hline Researchers & $\mathrm{N}$ & Predictors & Non Predictors & $\begin{array}{l}\text { Outcome } \\
\text { Variable(s) }\end{array}$ \\
\hline $\begin{array}{l}\text { Seivewright, } \\
\text { Tyrer, \& } \\
\text { Johnson, } 1998\end{array}$ & $\begin{array}{l}210 \\
\text { psychiatric } \\
\text { outpatients }\end{array}$ & $\begin{array}{l}\text { Poorer prognosis } \\
\text { predicted by older } \\
\text { age, presence of } \\
\text { personality } \\
\text { disorder at } \\
\text { baseline, and the } \\
\text { presence of a } \\
\text { general neurotic } \\
\text { syndrome at } \\
\text { baseline }\end{array}$ & $\begin{array}{l}\text { Sex, marital status, } \\
\text { social class, treatment } \\
\text { randomization group, } \\
\text { DSM-III diagnosis at } \\
\text { baseline, duration of } \\
\text { symptoms, single or } \\
\text { recurrent episodes, } \\
\text { life stress, baseline } \\
\text { total scores on a } \\
\text { measure of general } \\
\text { psychopathology, } \\
\text { depression scores, } \\
\text { anxiety scores, } \\
\text { number of comorbid } \\
\text { symptoms }\end{array}$ & $\begin{array}{l}\text { Health service } \\
\text { utilization }\end{array}$ \\
\hline $\begin{array}{l}\text { Haby, } \\
\text { Donnelly, } \\
\text { Corry \& Vos, } \\
2006\end{array}$ & $\begin{array}{l}\text { Pooled } \\
\text { data }\end{array}$ & $\begin{array}{l}\text { Poorer outcomes } \\
\text { were associated } \\
\text { with inclusion of } \\
\text { greater severity at } \\
\text { baseline, presence } \\
\text { of a waitlist } \\
\text { control group } \\
\text { instead of an } \\
\text { attention control. }\end{array}$ & $\begin{array}{l}\text { Treatment type, year } \\
\text { of study, length of } \\
\text { trial, country of } \\
\text { study, language and } \\
\text { number of dropouts } \\
\text { from the control } \\
\text { group }\end{array}$ & $\begin{array}{l}\text { Symptom } \\
\text { levels, } \\
\text { Functioning } \\
\text { Health-related } \\
\text { quality of life } \\
\text { measures }\end{array}$ \\
\hline $\begin{array}{l}\text { Durham, } \\
\text { Allan, \& } \\
\text { Hackett, } 1997\end{array}$ & $\mathrm{~N}=80$ & $\begin{array}{l}\text { Being married } \\
\text { was associated } \\
\text { with better } \\
\text { outcomes, and } \\
\text { marital tension } \\
\text { predicted poorer } \\
\text { outcomes. } \\
\text { Presence of other } \\
\text { Axis I diagnoses } \\
\text { predicted poorer } \\
\text { outcomes. }\end{array}$ & $\begin{array}{l}\text { Screening variables, } \\
\text { referral variables }\end{array}$ & $\begin{array}{l}\text { Sustained } \\
\text { improvement, } \\
\text { relapse and no } \\
\text { consistent } \\
\text { change }\end{array}$ \\
\hline
\end{tabular}




\begin{tabular}{|c|c|c|c|c|}
\hline $\begin{array}{l}\text { Wetherell et } \\
\text { al., } 2005\end{array}$ & $\mathrm{~N}=65$ & $\begin{array}{l}\text { Better outcomes } \\
\text { were associated } \\
\text { with higher GAD } \\
\text { severity at } \\
\text { baseline, presence } \\
\text { of Axis I } \\
\text { comorbidity, and } \\
\text { more frequent } \\
\text { homework }\end{array}$ & $\begin{array}{l}\text { Age, gender, } \\
\text { ethnicity, education, } \\
\text { work status, duration } \\
\text { of episode, sessions } \\
\text { attended }\end{array}$ & $\begin{array}{l}\text { Reliable } \\
\text { change indices }\end{array}$ \\
\hline
\end{tabular}


Table 3

Demographic and Participant Characteristics by Diagnosis

\begin{tabular}{|c|c|c|}
\hline & $\operatorname{GAD}(\mathrm{N}=177)$ & Control $(\mathrm{N}=41)$ \\
\hline \multicolumn{3}{|l|}{ Age } \\
\hline Mean & 71.58 & 75.12 \\
\hline $\mathrm{SD}$ & 7.74 & 6.26 \\
\hline Range & $60-89$ & $62-88$ \\
\hline \multicolumn{3}{|l|}{ Gender } \\
\hline Male $(\%)$ & 32.3 & 33.3 \\
\hline Female (\%) & 66.1 & 66.7 \\
\hline \multicolumn{3}{|l|}{ Education (years) } \\
\hline Mean & 13.86 & 14.48 \\
\hline $\mathrm{SD}$ & 2.90 & 2.87 \\
\hline Range & $2-20$ & $7-20$ \\
\hline \multicolumn{3}{|l|}{ Marital } \\
\hline Never Married (\%) & 9.4 & 7.9 \\
\hline Married (\%) & 52.6 & 68.4 \\
\hline Separated & 1.8 & 2.6 \\
\hline Divorced (\%) & 12.3 & 7.9 \\
\hline Widowed (\%) & 22.8 & 13.2 \\
\hline Cohabitating (\%) & 1.2 & 0.0 \\
\hline
\end{tabular}


Table 3 (continued)

\begin{tabular}{lcc}
\hline Ethnicity & 81.9 & 92.9 \\
Caucasian (\%) & 17.5 & 7.1 \\
African American (\%) & 0.6 & 0.0 \\
Asian Pacific (\%) & & \\
Job Status & 5.3 & 0.0 \\
Disabled (\%) & 7.6 & 2.6 \\
Working Full Time (\%) & 9.4 & 5.3 \\
Working Part Time (\%) & 8.2 & 5.3 \\
Homemaker (\%) & 6.4 & 0.0 \\
Unemployed (\%) & 63.2 & 86.8 \\
Retired (\%) & & \\
\hline
\end{tabular}


Table 4

Means for Outcome Measures for all participants with GAD at Baseline

$$
\text { GAD }
$$

\begin{tabular}{|c|c|c|}
\hline Measure & $\underline{M}$ & $\underline{\mathrm{SD}}$ \\
\hline PSWQ & 51.86 & 15.96 \\
\hline SF-36 MC & 44.89 & 10.86 \\
\hline $\mathrm{SF}-36 \mathrm{PC}$ & 42.65 & 10.64 \\
\hline Salivary Cortisol (AUC) & 29.25 & 10.69 \\
\hline
\end{tabular}


Table 5

Group differences for outcome measures at baseline and week 12 for participants with GAD who were randomized to medication

\begin{tabular}{|c|c|c|c|c|c|}
\hline \multirow[b]{2}{*}{ Outcome measure } & \multicolumn{2}{|c|}{ Baseline scores } & \multicolumn{2}{|c|}{ Week 12 scores } & \multirow[b]{2}{*}{$\underline{\mathrm{t}}(138)$} \\
\hline & $\underline{M}$ & $\underline{\mathrm{SD}}$ & $\underline{\mathrm{M}}$ & $\underline{\mathrm{SD}}$ & \\
\hline PSWQ & 54.29 & 12.46 & 47.76 & 12.30 & $.001 * *$ \\
\hline SF-36 MC & 42.24 & 8.89 & 47.29 & 8.74 & $.001 * *$ \\
\hline SF-36 PC & 39.72 & 11.16 & 39.85 & 11.48 & .89 \\
\hline Salivary cortisol (AUC) & 29.43 & 10.91 & 25.72 & 12.79 & .23 \\
\hline
\end{tabular}


Table 6

Correlations Between Baseline and Week 12 Administration of Predictor and Outcome Measures

\begin{tabular}{|c|c|c|c|c|c|c|c|c|c|c|}
\hline Measure & 1 & 2 & 3 & 4 & 5 & 6 & 7 & 8 & 9 & $10 \quad 11$ \\
\hline $\begin{array}{l}\text { 1. PSWQ } \\
\text { Baseline }\end{array}$ & -- & & & & & & & & & \\
\hline $\begin{array}{l}\text { 2. PSWQ } \\
\text { Week } 12\end{array}$ & $.80 * *$ & -- & & & & & & & & \\
\hline $\begin{array}{l}\text { 3. SF-36 } \\
\mathrm{MC} \\
\text { Baseline }\end{array}$ & $-.43 * *$ & $-.52 * *$ & -- & & & & & & & \\
\hline $\begin{array}{l}\text { 4. SF-36 } \\
\text { MC } \\
\text { Week } 12\end{array}$ & -.16 & -.45 & $.52 * *$ & -- & & & & & & \\
\hline $\begin{array}{l}\text { 5. SF-36 } \\
\text { PC } \\
\text { Baseline }\end{array}$ & .13 & $.29 *$ & -.27 & -.08 & -- & & & & & \\
\hline $\begin{array}{l}\text { 6. SF-36 } \\
\text { PC } \\
\text { Week } 12\end{array}$ & .18 & $.28 *$ & -.22 & -.15 & $.79 * *$ & -- & & & & \\
\hline $\begin{array}{l}7 . \\
\text { Salivary } \\
\text { Cortisol } \\
\text { AUC } \\
\text { Baseline }\end{array}$ & .32 & .20 & -.16 & -.16 & .26 & .17 & -- & & & \\
\hline $\begin{array}{l}8 . \\
\text { Salivary } \\
\text { Cortisol } \\
\text { AUC } \\
\text { Week } 12\end{array}$ & .14 & .19 & -.25 & -.15 & .22 & .03 & .30 & -- & & \\
\hline $\begin{array}{l}\text { 9. CGI-I } \\
\text { Week } 12\end{array}$ & .15 & $.39 * *$ & -.15 & $-.46 * *$ & -.19 & -.23 & .19 & .19 & -- & \\
\hline 10. & $.32 * *$ & $.24^{*}$ & -.19 & $-.30 *$ & .01 & .11 & -.19 & .12 & -.05 & \\
\hline
\end{tabular}


"Anxious

Mood"

item

Baseline

11.

"Tension"

.07

$\begin{array}{lll}.04 & -.24 * & -.07\end{array}$

$-.12$

$-.17 \quad .04$

$\begin{array}{lllll}-.03 & -.05 & .02 & -\end{array}$

Week 12

${ }^{*} \mathrm{p}<.01 .{ }^{* *} \mathrm{p}<.001$. 
Table 7

Differences Between SIGH-A Cluster Item Scores in the GAD and Control Group

\begin{tabular}{|c|c|c|c|c|c|}
\hline & \multicolumn{2}{|c|}{$\begin{array}{c}\underline{\text { GAD }} \\
(\mathrm{n}=177)\end{array}$} & \multicolumn{2}{|c|}{$\begin{array}{l}\text { No GAD } \\
(\mathrm{n}=41)\end{array}$} & \multirow[b]{2}{*}{$\underline{t}(216)$} \\
\hline Symptom Cluster & $\underline{\mathrm{M}}$ & $\underline{\mathrm{SD}}$ & $\underline{\mathrm{M}}$ & $\underline{\mathrm{SD}}$ & \\
\hline 1. Anxious Mood & 3.01 & .34 & .34 & .53 & $40.65 * *$ \\
\hline 2. Tension & 2.70 & .58 & .29 & .56 & $24.20 * *$ \\
\hline 3. Fears & .59 & .87 & .02 & .16 & $4.15^{* *}$ \\
\hline 4. Insomnia & 2.76 & .84 & .98 & 1.06 & $11.62 * *$ \\
\hline 5. Concentration & 1.77 & .93 & .49 & .64 & $8.42 * *$ \\
\hline 6. Depressed & 1.34 & .92 & 0.00 & 0.00 & $9.41 * *$ \\
\hline \multicolumn{6}{|l|}{ Mood } \\
\hline 7. Somatic & 2.28 & .98 & .73 & 1.00 & $9.09 * *$ \\
\hline \multicolumn{6}{|l|}{ Muscular } \\
\hline 8. Somatic & 1.49 & 1.12 & .46 & .64 & $6.19 * *$ \\
\hline \multicolumn{6}{|l|}{ Sensory } \\
\hline 9. Cardiovascular & .60 & .86 & .15 & .48 & $3.27 * *$ \\
\hline 10. Respiratory & 1.19 & .96 & .10 & .30 & $7.24 * *$ \\
\hline 11. Gastro- & 1.80 & 1.04 & .68 & .85 & $6.43 * *$ \\
\hline
\end{tabular}


12. Genito-

urinary

13. Autonomic

1.13

14. Interview

1.41

Behavior
.99

.65

$\begin{array}{llll}1.14 & .32 & .88 & 3.12 *\end{array}$

.15

.48

$6.21 * *$

.27

$12.71 * *$

${ }^{*} \mathrm{p}<.01 .{ }^{*} * \mathrm{p}<.001$. 
Table 8

Classification Results for Discriminant Function Analysis

\begin{tabular}{|c|c|c|c|c|c|}
\hline \multirow[b]{3}{*}{ Actual Group Membership } & \multirow[b]{3}{*}{$\underline{\mathrm{n}}$} & \multicolumn{4}{|c|}{ Predicted group membership } \\
\hline & & \multicolumn{2}{|c|}{ GAD } & \multicolumn{2}{|c|}{ No GAD } \\
\hline & & $\underline{\mathrm{n}}$ & $\%$ & $\underline{\mathrm{n}}$ & $\%$ \\
\hline GAD & 41 & 41 & 100.0 & 0 & 0.0 \\
\hline No GAD & 177 & 0 & 0.0 & 177 & 100.0 \\
\hline
\end{tabular}

Note. Overall percentage of correctly classified cases $=100.0 \%$ 
Table 9

Regression Models for Predicting Outcomes of GAD Using SIGH-A Clusters as Predictors

\begin{tabular}{|c|c|c|c|c|c|}
\hline Variable & $\underline{\mathrm{B}}$ & $\underline{\text { SEB }}$ & $\underline{\beta}$ & $\underline{\mathrm{R}^{2}}$ & $\underline{\Delta \mathrm{R}^{2}}$ \\
\hline \multicolumn{6}{|l|}{ PSWQ } \\
\hline Model 1 & & & & $.65 * *$ & $.65 * *$ \\
\hline Baseline PSWQ & .79 & .07 & $.80 * *$ & & \\
\hline Model 2 & & & & $.65 * *$ & .003 \\
\hline Baseline PSWQ & .78 & .08 & .79 & & \\
\hline Baseline "Anxious Mood" & 2.36 & 4.58 & .04 & & \\
\hline Baseline "Tension" & -.83 & 1.81 & -.03 & & \\
\hline \multicolumn{6}{|l|}{$\mathrm{SF}-36 \mathrm{MC}$} \\
\hline Model 1 & & & & $.28 * *$ & $.28 * *$ \\
\hline Baseline SF-36 MC & .52 & .10 & $.52 * *$ & & \\
\hline Model 2 & & & & $.30 * *$ & .03 \\
\hline Baseline SF-36 MC & .50 & .11 & $.51 * *$ & & \\
\hline Baseline "Anxious Mood" & -6.24 & 4.41 & -.15 & & \\
\hline Baseline "Tension" & .91 & 1.87 & .05 & & \\
\hline \multicolumn{6}{|l|}{ SF-36PC } \\
\hline Model 1 & & & & $.62 * *$ & $.62 * *$ \\
\hline Baseline SF-36 PC & .81 & .08 & $.79 * *$ & & \\
\hline Model 2 & & & & $.64 * *$ & .02 \\
\hline Baseline SF-36 PC & .80 & .08 & $.78 * *$ & & \\
\hline Baseline "Anxious Mood" & 5.58 & 4.11 & .10 & & \\
\hline Baseline "Tension" & -1.63 & 1.73 & -.07 & & \\
\hline \multicolumn{6}{|l|}{ CGI-I } \\
\hline Model 1 & & & & .008 & .008 \\
\hline Baseline "Anxious Mood" & -.17 & .41 & -.05 & & \\
\hline Baseline "Tension" & .13 & .22 & .07 & & \\
\hline \multicolumn{6}{|l|}{ Salivary Cortisol AUC } \\
\hline Model 1 & & & & .09 & .09 \\
\hline Baseline AUC & .35 & .25 & .30 & & \\
\hline Model 2 & & & & .12 & .04 \\
\hline Baseline PSWQ & .39 & .26 & .34 & & \\
\hline Baseline "Anxious Mood" & 11.30 & 13.57 & .19 & & \\
\hline Baseline "Tension" & -1.18 & 4.50 & -.06 & & \\
\hline
\end{tabular}

$* \mathrm{p}<.01 . * * \mathrm{p}<.001$. 


\section{Appendix A}

\section{Structured Interview Guide for the Hamilton Anxiety Rating Scale (SIGH-A)}

The purpose of this interview guide is to assist in the reliable assessment of anxiety severity by standardizing the method of assessment and providing clear anchor points for the assignment of severity ratings. The interview items and the anchor points are meant to supplement good clinical judgment, not replace it. To ensure full assessment of the domain of inquiry for each item, the interviewer should ask all questions provided. These defining characteristics are meant to aid in the reliable use of the severity scales; they represent examples of the severity levels appropriate to the rating, Severity is defined most readily the frequency of occurrence, degree of distress and interference associated with the symptom. The number of symptoms present is included in the severity rating only as it impacts on distress and interference. For example, a higher rating may be achieved for a single severe symptom and for several mild to moderate symptoms. Alternatively, several mild symptoms may lead to a moderate rating of severity because of their overall impact on distress.

In addition to the guidelines for each item, the interviewer should note the following conventions for boundary problems:

A. None to mild boundary: Most questionable cases should be rated as one, as zero is meant to be an anchor point with no symptoms present.

B. Mild to moderate boundary: Symptoms are endorsed less than fifty percent of the time and cause little or no interference or distress; rate as one. Symptoms are endorsed less than fifty percent of the time and are rated as causing mild to moderate interference or distress; rate as two. Symptoms are endorsed more than fifty percent of the time and are rated as causing mild interference or distress; rate as two.

C. Moderate to severe boundary: Symptoms are endorsed less than fifty percent of the time and are rated as causing severe interference or distress; rate as three. Symptoms are endorsed more than fifty percent of the time and are rated as causing moderate to severe interference or distress, but not both; rate as three.

D. Severe to very severe boundary: Questionable cases should generally be rated as three, ratings of four are reserved for behavioral events clearly identified by the rating anchors.

To elicit information necessary for assigning severity ratings, the interviewer must assess the frequency of occurrence, degree of distress, and degree of interference associated with the symptoms. The following questions are recommended for this assessment:

A. Have you have the symptom every day? IF NO, Have you had the symptom more days than not?

B. How much does the symptom bother you?

C. How much does it interfere with your life?

Starting the interview: Begin the interview with an introduction, describing the scale and its purpose in a way that is relevant for the specific patient and for the specific assessment. For 
example, for the first administration, one might say, "As you know, we have diagnosed your condition as an anxiety disorder. We are now going to be asking you a number of questions about different aspects of your anxiety. Together, they allow us to rate as accurately as possible the overall severity of your anxiety state. We will be rating anxiety severity in this way at different points in your treatment in order to decide how much the treatment is helping you." This example is not meant as a script. The interviewer should introduce the scale in a way most comfortable for the patient and for her/his own style.

It is assumed that the interviewer has completed a previous diagnostic interview and is familiar with the patient's general range of symptoms. If this is not true, the interviewer should preface the Hamilton Anxiety Scale by asking for a summary (five or ten minutes) of the patient's specific worries, disturbing physical symptoms, duration of the syndrome, and its characteristics over time (e.g. Does it tend to wax and wane, or has it been persistent since the onset?). The interviewer should also obtain a global statement on distress and impairment during the last week, and the cause of this distress. This information will provide the rater with a background or framework from which to conduct the ratings.

Although there are differences between studies, it is assumed that all ratings for the Hamilton Anxiety Rating Scale for patients with panic disorder will focus exclusively on times other than panic episodes. 


\section{Anxious Mood}

What's your mood been like this week?

Have you been feeling anxious?

Nervous?

Worrying?

Feeling something bad may happen?

Feeling irritable?

\section{Tension}

Have you been feeling tense?

Do you startle easily?

Cry easily?

Fatigue easily?

Have you been trembling?

Feeling restless?

Unable to relax?
0- No anxious mood

1- Mild worry or anxiety indicated only on questioning; no change in functioning

2- Preoccupation with minor events, anxiety on as many days as not

3- Nearly daily episodes of anxiety/ worry with disruption of daily activities; daily preoccupation

4- Nearly constant anxiety; significant role disruption

0- No tension

1- Several days of mild tension or occasional (e.g., 1-2) episodes of exaggerated startle or labile mood

2- Muscle tension or fatigue $50 \%$ of the time or repeated $(>2)$ episodes of trembling, exaggerated startle, etc.

3- Nearly daily muscle tension, fatigue and/or restlessness $>75 \%$ of the time or persistent, disruptive symptoms

4- Constant tension, restlessness, agitation, unable to relax in the interview 


\section{Fears}

Have you been feeling fearful (phobic) of situations or events?

For example, have you been afraid of the dark?

Of strangers?

Of being left alone?

Of animals?

Of being caught in traffic?

Of crowds?

Other fears? $0-\quad$ No fears

1- Mild phobic concerns that do not cause significant distress or disrupt functioning

2- Fears lead to distress or avoidance on one or more occasions

3- Fears are an object of concern on a near daily basis (75\%); patient may need to be accompanied by others to a fearful event

4- Fears or avoidance that markedly affect function. Patient may avoid multiple situations even if accompanied; extensive agoraphobia

0- No sleep disturbance

1- Mildly disrupted sleep (e.g., one or two nights of difficulties falling asleep or nightmares)

2- Several episodes of sleep disturbance that is regular but not persistent (e.g., over onehalf hour falling asleep, nightmares, or excessive AM fatigue)

3- Persistent sleep disruption (on more days than not), characterized by difficulty falling asleep (e.g., over one half hour) or staying asleep, restlessness, unsatisfying sleep or frequent nightmares, or fatigue

4- Nightly difficulties with sleep onset or maintenance, or daily severe fatigue on waking in the AM 


\section{Concentration}

Have you had trouble concentrating?

Remembering things?

\section{Depressed Mood}

Have you been feeling depressed?

Have you lost interest in things?

Do you get pleasure from friends or hobbies?
0- No difficulties

1- Infrequent episodes of forgetfulness or difficulty concentrating that are not distressing to the patient

2- Recurrent episodes of forgetfulness or difficulty concentrating, or episodes of sufficient intensity to cause the patient recurrent concern

3- Persistent concentration or memory impairment that interferes with daily tasks

4- Significant role impairment due to concentration difficulties

0- No depression

1- Occasional or mild blue or sad mood, or reports of decreased enjoyment of activities

2- Sad or blue mood or disinterest $50 \%$ of the time, mood does not generally interfere with functioning

3- Persistent depressed mood or loss of pleasure, mood is significantly distressing to patient, or may be evident to others

4- Daily evidence of severe depression with significant role impairment 


\section{Somatic Muscular}

Have you been experiencing any aches, pains, or stiffness in your muscles?

Have you experienced any muscle twitching or sudden muscle jerks? Have you had an unsteady voice?

\section{Somatic Sensory}

Have you been experiencing any ringing in your ears?

Blurred vision?

Hot or cold flashed?

Feelings of weakness?

Or prickling sensations?
0- No muscular symptoms

1- Infrequent presence of one or two symptoms, no significant distress

2- Mild distress over several symptoms or moderate distress over a single symptom

3- Symptoms occur on more days than not, symptoms are associated with moderate to severe distress and/or regular attempts at symptom control by limiting activities or taking medications

4- Daily or near daily episodes of symptoms that cause the patient significant distress and lead to restriction of activities or repeated visits for medical attention

0- No symptoms

1- Infrequent presence of one or two symptoms, no significant distress

2- Mild distress over several symptoms or moderate distress over a single symptom

3- Symptoms occur on more days than not, symptoms are associated with moderate to severe distress and/or regular attempts at symptom control by limiting activities or taking medications

4- Daily or near daily episodes of symptoms that cause the patient significant distress and lead to restriction of activities or repeated visits for medical attention 


\section{Cardiovascular}

Have you had episodes of a racing, skipping, or pounding heart?

How about pain in your chest? Fainting feelings?

\section{Respiratory}

Have you been having trouble with your breathing?

Any pressure or constriction in your chest?

Choking feelings?

Sighing?

or Feeling like you can't catch your breath?
0- No symptoms

1- Infrequent presence of one or two symptoms, no significant distress

2- Mild distress over several symptoms or moderate distress over a single symptom

3- Symptoms occur on more days than not, symptoms are associated with moderate to severe distress and/or regular attempts at symptom control by limiting activities or taking medications

4- Daily or near daily episodes of symptoms that cause the patient significant distress and lead to restriction of activities or repeated visits for medical attention

0- No symptoms

1- Infrequent presence of one or two symptoms, no significant distress

2- Mild distress over several symptoms or moderate distress over a single symptom

3- Symptoms occur on more days than not, symptoms are associated with moderate to severe distress and/or regular attempts at symptom control by limiting activities or taking medications

4- Daily or near daily episodes of symptoms that cause the patient significant distress and lead to restriction of activities or repeated visits for medical attention 


\section{Gastro-intestinal}

Have you had any stomach pain or discomfort?

Nausea or vomiting?

Burning or rumbling in your stomach?

Heartburn?

Loose bowels?

Constipation?

Sinking feeling in your stomach?

\section{Genito-urinary}

Have you been experiencing any urinary difficulties?

For example, have you had to urinate more frequently than usual?

Have you had more urgency to urinate?

Have you had decreased sexual interest?
0- No symptoms

1- Infrequent and minor episodes of gastric discomfort, constipation, or loosening of bowel, fleeting nausea

2- An episode of vomiting or recurrent episodes of abdominal pain, loosening of bowels, difficulty swallowing, etc.

3- Symptoms more days than not that are very bothersome to the patient or lead to concerns over eating, bathroom availability, or use of medication

4- Daily or near daily episodes of symptoms that cause the patient significant distress and lead to restriction of activities or visits for medical attention

0- No symptoms

1- Infrequent or minor urinary symptoms or mild changes in sexual interest

2- Urinary symptoms several days during the week, occasional difficulties with sexual functioning

3- Urinary or sexual symptoms more days than not

4- Daily urinary or sexual symptoms that lead to distress and medical care seeking 


\section{Autonomic}

Have you been experiencing any

flushing in your face?

Getting pale?

Lightheadedness?

Have you been having any tension headaches?

Have you felt the hair rise on your arms, the back of your neck or head, as though something had frightened you?

\section{Behavior}

Rate Interview Behavior Fidgeting, restlessness or pacing, tremor of hands, furrowed brow, strained face, sighing or rapid respirations, facial pallor, frequent swallowing, etc.
0- No symptoms

1- Mild symptoms that occur infrequently

2- Symptoms occurred several times during the week and were bothersome

3- Near daily symptoms with distress or embarrassment about the symptoms

4- Daily symptoms that are a focus of distress and impair function (e.g. daily headaches or lightheadedness leading to limitation of activities)

0- No apparent symptoms

1- Presence of one or two symptoms to a mild degree

2- Presence of several symptoms of mild intensity or one symptom of moderate intensity

3- Persistent symptoms throughout the interview

4- Agitation, hyperventilation, difficulty completing the interview 


\section{Appendix B}

\section{Penn State Worry Questionnaire}

Enter the number that best describes how typical or characteristic each item is of you, putting the number next to the item.

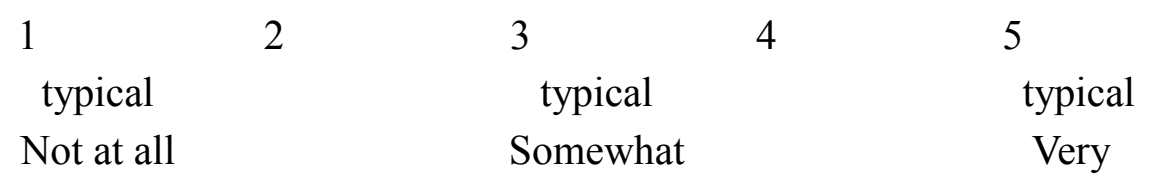

1. If I don't have enough time to do everything, I don't worry about it.

2. My worries overwhelm me.

3. I do not tend to worry about things.

4. Many situations make me worry.

5. I know I shouldn’t worry about things, but I just cannot help it.

6. When I am under pressure I worry a lot.

7. I am always worrying about something.

8. I find it easy to dismiss worrisome thoughts.

9. As soon as I finish one task, I start to worry about everything else I have to

do.

10. I never worry about anything.

11. When there is nothing more I can do about a concern, I don't worry about it anymore.

12. I've been a worrier all my life.

13. I notice that $\mathrm{I}$ have been worrying about things.

14. Once I start worrying, I can't stop.

15. I worry all the time.

16. I worry about projects until they are done. 


\section{Appendix C}

SF-36

1. In general, would you say your health is:

\begin{tabular}{|c|c|c|c|c|}
\hline Excellent & Very Good & Good & Fair & Poor \\
\hline 1 & 2 & 3 & 4 & 5 \\
\hline
\end{tabular}

2. Compared to one year ago, how would you rate your health in general now?

\begin{tabular}{|c|c|c|c|c|}
\hline $\begin{array}{c}\text { Much Better } \\
\text { than one year } \\
\text { ago }\end{array}$ & $\begin{array}{c}\text { Somewhat } \\
\text { better now than } \\
\text { one year ago }\end{array}$ & $\begin{array}{c}\text { About the same } \\
\text { as one year ago }\end{array}$ & $\begin{array}{c}\text { Somewhat } \\
\text { worse now than } \\
\text { one year ago }\end{array}$ & $\begin{array}{c}\text { Much worse } \\
\text { now than one } \\
\text { year ago }\end{array}$ \\
\hline 1 & 2 & 3 & 4 & 5 \\
\hline
\end{tabular}

3. The following items are about activities you might do during a typical day. Does your health now limit you in these activities? If so, how much?

a. Vigorous activities, such as running, lifting heavy objects, participating in strenuous sports

\begin{tabular}{|c|c|c|}
\hline Yes, Limited a lot & Yes, Limited a little & No, Not Limited at all \\
\hline 1 & 2 & 3 \\
\hline
\end{tabular}

b. Moderate activities, such as moving a table, pushing a vacuum cleaner, bowling, or playing golf

\begin{tabular}{|c|c|c|}
\hline Yes, Limited a lot & Yes, Limited a little & No, Not Limited at all \\
\hline 1 & 2 & 3 \\
\hline
\end{tabular}

c. Lifting or carrying groceries

\begin{tabular}{|c|c|c|}
\hline Yes, Limited a lot & Yes, Limited a little & No, Not Limited at all \\
\hline 1 & 2 & 3 \\
\hline
\end{tabular}

d. Climbing several flights of stairs

\begin{tabular}{|c|c|c|}
\hline Yes, Limited a lot & Yes, Limited a little & No, Not Limited at all \\
\hline 1 & 2 & 3 \\
\hline
\end{tabular}


e. Climbing one flight of stairs

\begin{tabular}{|c|c|c|}
\hline Yes, Limited a lot & Yes, Limited a little & No, Not Limited at all \\
\hline 1 & 2 & 3 \\
\hline
\end{tabular}

f. Bending, kneeling, or stooping

\begin{tabular}{|c|c|c|}
\hline Yes, Limited a lot & Yes, Limited a little & No, Not Limited at all \\
\hline 1 & 2 & 3 \\
\hline
\end{tabular}

g. Walking more than a mile

\begin{tabular}{|c|c|c|}
\hline Yes, Limited a lot & Yes, Limited a little & No, Not Limited at all \\
\hline 1 & 2 & 3 \\
\hline
\end{tabular}

h. Walking several blocks

\begin{tabular}{|c|c|c|}
\hline Yes, Limited a lot & Yes, Limited a little & No, Not Limited at all \\
\hline 1 & 2 & 3 \\
\hline
\end{tabular}

i. Walking one block

\begin{tabular}{|c|c|c|}
\hline Yes, Limited a lot & Yes, Limited a little & No, Not Limited at all \\
\hline 1 & 2 & 3 \\
\hline
\end{tabular}

j. Bathing or dressing yourself

\begin{tabular}{|c|c|c|}
\hline Yes, Limited a lot & Yes, Limited a little & No, Not Limited at all \\
\hline 1 & 2 & 3 \\
\hline
\end{tabular}

4. During the past 4 weeks, have you had any of the following problems with your work or other regular daily activities as a result of your physical health?

a. Cut down the amount of time you spent on work or other activities.

$$
\text { Yes }=1 \quad \text { No }=0
$$


b. Accomplished less than you would like

$$
\text { Yes }=1 \quad \text { No }=0
$$

c. Were limited in the kind of work or other activities

$$
\text { Yes }=1 \quad \text { No }=0
$$

d. Had difficulty performing the work or other activities (for example, it took extra effort)

$$
\text { Yes }=1 \quad \text { No }=0
$$

5. During the past 4 weeks, have you had any of the following problems with your work or other regular daily activities as a result of any emotional problems (such as feeling depressed or anxious)?

a. Cut down the amount of time you spent on work or other activities

$$
\text { Yes }=1 \quad \text { No }=0
$$

b. Accomplished less than you would like

$$
\text { Yes }=1 \quad \text { No }=0
$$

c. Didn't do work or other activities as carefully as usual

$$
\text { Yes }=1 \quad \text { No }=0
$$

6. During the past 4 weeks, to what extent has your physical health or emotional problems interfered with your normal social activities with family, friends, neighbors, or groups?

\begin{tabular}{|c|c|c|c|c|}
\hline Not at all & Slightly & Moderately & Quite a bit & Extremely \\
\hline 0 & 1 & 2 & 3 & 4 \\
\hline
\end{tabular}

7. How much bodily pain have you had during the past 4 weeks?

\begin{tabular}{|c|c|c|c|c|c|}
\hline None & Very Mild & Mild & Moderate & Severe & Very Severe \\
\hline 0 & 1 & 2 & 3 & 4 & 5 \\
\hline
\end{tabular}


8. During the past 4 weeks, how much did pain interfere with your normal work including both work outside the home and housework)?

\begin{tabular}{|c|c|c|c|c|}
\hline Not at all & Slightly & Moderately & Quite a bit & Extremely \\
\hline 0 & 1 & 2 & 3 & 4 \\
\hline
\end{tabular}

9. These questions are about how you feel and how things have been with you during the past 4 weeks. For each question, please give the one answer that comes closest to the way you have been feeling. How much of the time during the past 4 weeks:

a. Did you feel full of pep?

\begin{tabular}{|c|c|c|c|c|c|}
\hline $\begin{array}{c}\text { All of the } \\
\text { time }\end{array}$ & $\begin{array}{c}\text { Most of the } \\
\text { time }\end{array}$ & $\begin{array}{c}\text { Some of } \\
\text { the time }\end{array}$ & $\begin{array}{c}\text { A good bit } \\
\text { of the time }\end{array}$ & $\begin{array}{c}\text { A little of } \\
\text { the time }\end{array}$ & $\begin{array}{c}\text { None of the } \\
\text { time }\end{array}$ \\
\hline 0 & 1 & 2 & 3 & 4 & 5 \\
\hline
\end{tabular}

b. Have you been a very nervous person?

\begin{tabular}{|c|c|c|c|c|c|}
\hline $\begin{array}{c}\text { All of the } \\
\text { time }\end{array}$ & $\begin{array}{c}\text { Most of the } \\
\text { time }\end{array}$ & $\begin{array}{c}\text { Some of } \\
\text { the time }\end{array}$ & $\begin{array}{c}\text { A good bit } \\
\text { of the time }\end{array}$ & $\begin{array}{c}\text { A little of } \\
\text { the time }\end{array}$ & $\begin{array}{c}\text { None of the } \\
\text { time }\end{array}$ \\
\hline 0 & 1 & 2 & 3 & 4 & 5 \\
\hline
\end{tabular}

c. Have you felt so down in the dumps that nothing could cheer you up?

\begin{tabular}{|c|c|c|c|c|c|}
\hline $\begin{array}{c}\text { All of the } \\
\text { time }\end{array}$ & $\begin{array}{c}\text { Most of the } \\
\text { time }\end{array}$ & $\begin{array}{c}\text { Some of } \\
\text { the time }\end{array}$ & $\begin{array}{c}\text { A good bit } \\
\text { of the time }\end{array}$ & $\begin{array}{c}\text { A little of } \\
\text { the time }\end{array}$ & $\begin{array}{c}\text { None of the } \\
\text { time }\end{array}$ \\
\hline 0 & 1 & 2 & 3 & 4 & 5 \\
\hline
\end{tabular}

d. Have you felt calm and peaceful?

\begin{tabular}{|c|c|c|c|c|c|}
\hline $\begin{array}{c}\text { All of the } \\
\text { time }\end{array}$ & $\begin{array}{c}\text { Most of the } \\
\text { time }\end{array}$ & $\begin{array}{c}\text { Some of } \\
\text { the time }\end{array}$ & $\begin{array}{c}\text { A good bit } \\
\text { of the time }\end{array}$ & $\begin{array}{c}\text { A little of } \\
\text { the time }\end{array}$ & $\begin{array}{c}\text { None of the } \\
\text { time }\end{array}$ \\
\hline 0 & 1 & 2 & 3 & 4 & 5 \\
\hline
\end{tabular}

e. Did you have a lot or energy?

\begin{tabular}{|c|c|c|c|c|c|}
\hline $\begin{array}{c}\text { All of the } \\
\text { time }\end{array}$ & $\begin{array}{c}\text { Most of the } \\
\text { time }\end{array}$ & $\begin{array}{c}\text { Some of } \\
\text { the time }\end{array}$ & $\begin{array}{c}\text { A good bit } \\
\text { of the time }\end{array}$ & $\begin{array}{c}\text { A little of } \\
\text { the time }\end{array}$ & $\begin{array}{c}\text { None of the } \\
\text { time }\end{array}$ \\
\hline 0 & 1 & 2 & 3 & 4 & 5 \\
\hline
\end{tabular}


f. Have you felt downhearted and blue?

\begin{tabular}{|c|c|c|c|c|c|}
\hline $\begin{array}{c}\text { All of the } \\
\text { time }\end{array}$ & $\begin{array}{c}\text { Most of the } \\
\text { time }\end{array}$ & $\begin{array}{c}\text { Some of } \\
\text { the time }\end{array}$ & $\begin{array}{c}\text { A good bit } \\
\text { of the time }\end{array}$ & $\begin{array}{c}\text { A little of } \\
\text { the time }\end{array}$ & $\begin{array}{c}\text { None of the } \\
\text { time }\end{array}$ \\
\hline 0 & 1 & 2 & 3 & 4 & 5 \\
\hline
\end{tabular}

g. Did you feel worn out?

\begin{tabular}{|c|c|c|c|c|c|}
\hline $\begin{array}{c}\text { All of the } \\
\text { time }\end{array}$ & $\begin{array}{c}\text { Most of the } \\
\text { time }\end{array}$ & $\begin{array}{c}\text { Some of } \\
\text { the time }\end{array}$ & $\begin{array}{c}\text { A good bit } \\
\text { of the time }\end{array}$ & $\begin{array}{c}\text { A little of } \\
\text { the time }\end{array}$ & $\begin{array}{c}\text { None of the } \\
\text { time }\end{array}$ \\
\hline 0 & 1 & 2 & 3 & 4 & 5 \\
\hline
\end{tabular}

h. Have you been a happy person?

\begin{tabular}{|c|c|c|c|c|c|}
\hline $\begin{array}{c}\text { All of the } \\
\text { time }\end{array}$ & $\begin{array}{c}\text { Most of the } \\
\text { time }\end{array}$ & $\begin{array}{c}\text { Some of } \\
\text { the time }\end{array}$ & $\begin{array}{c}\text { A good bit } \\
\text { of the time }\end{array}$ & $\begin{array}{c}\text { A little of } \\
\text { the time }\end{array}$ & $\begin{array}{c}\text { None of the } \\
\text { time }\end{array}$ \\
\hline 0 & 1 & 2 & 3 & 4 & 5 \\
\hline
\end{tabular}

i. Did you feel tired?

\begin{tabular}{|c|c|c|c|c|c|}
\hline $\begin{array}{c}\text { All of the } \\
\text { time }\end{array}$ & $\begin{array}{c}\text { Most of the } \\
\text { time }\end{array}$ & $\begin{array}{c}\text { Some of } \\
\text { the time }\end{array}$ & $\begin{array}{c}\text { A good bit } \\
\text { of the time }\end{array}$ & $\begin{array}{c}\text { A little of } \\
\text { the time }\end{array}$ & $\begin{array}{c}\text { None of the } \\
\text { time }\end{array}$ \\
\hline 0 & 1 & 2 & 3 & 4 & 5 \\
\hline
\end{tabular}

10. During the past 4 weeks, how much of the time has your physical health or emotional problems interfered with your social activities (like visiting with friends, relatives, etc.)?

\begin{tabular}{|c|c|c|c|c|c|}
\hline $\begin{array}{c}\text { All of the } \\
\text { time }\end{array}$ & $\begin{array}{c}\text { Most of the } \\
\text { time }\end{array}$ & $\begin{array}{c}\text { Some of } \\
\text { the time }\end{array}$ & $\begin{array}{c}\text { A good bit } \\
\text { of the time }\end{array}$ & $\begin{array}{c}\text { A little of } \\
\text { the time }\end{array}$ & $\begin{array}{c}\text { None of the } \\
\text { time }\end{array}$ \\
\hline 0 & 1 & 2 & 3 & 4 & 5 \\
\hline
\end{tabular}

11. How TRUE or FALSE is each of the following statements for you?

a. I seem to get sick a little easier than other people

\begin{tabular}{|c|c|c|c|c|}
\hline $\begin{array}{c}\text { Definitely } \\
\text { True }\end{array}$ & Mostly True & Don't know & Mostly false & $\begin{array}{c}\text { Definitely } \\
\text { false }\end{array}$ \\
\hline 0 & 1 & 2 & 3 & 4 \\
\hline
\end{tabular}


b. I am as healthy as anybody I know

\begin{tabular}{|c|c|c|c|c|}
\hline $\begin{array}{c}\text { Definitely } \\
\text { True }\end{array}$ & Mostly True & Don't know & Mostly false & $\begin{array}{c}\text { Definitely } \\
\text { false }\end{array}$ \\
\hline 0 & 1 & 2 & 3 & 4 \\
\hline
\end{tabular}

c. I expect my health to get worse

\begin{tabular}{|c|c|c|c|c|}
\hline $\begin{array}{c}\text { Definitely } \\
\text { True }\end{array}$ & Mostly True & Don’t know & Mostly false & $\begin{array}{c}\text { Definitely } \\
\text { false }\end{array}$ \\
\hline 0 & 1 & 2 & 3 & 4 \\
\hline
\end{tabular}

d. My health is excellent

\begin{tabular}{|c|c|c|c|c|}
\hline $\begin{array}{c}\text { Definitely } \\
\text { True }\end{array}$ & Mostly True & Don't know & Mostly false & $\begin{array}{c}\text { Definitely } \\
\text { false }\end{array}$ \\
\hline 0 & 1 & 2 & 3 & 4 \\
\hline
\end{tabular}




\section{Appendix D}

\section{Clinical Global Impression - Global Improvement (CGI -I) Scale}

Rate total improvement whether or not, in your clinical judgment, it is due entirely to drug treatment.

Compared to baseline, how much has he/she changed?
$\square 0=$ Not assessed
$\square 1$ = Very much improved
$\square 2$ = Much improved
$\square 3$ = Minimally improved
$\square 4$ = No change
$\square 5$ = Minimally worse
$\square 6=$ Much worse
$\square 7$ = Very much worse 